\title{
MOTIVATION FOR MONEY AND CARE THAT ADULT CHILDREN PROVIDE FOR PARENTS: EVIDENCE FROM "POINT-BLANK" SURVEY QUESTIONS
}

\author{
Donald Cox* \\ Beth J. Soldo \\ CRR WP 2004-17 \\ Released: May 2004 \\ Draft Submitted: April 2004
Center for Retirement Research at Boston College
550 Fulton Hall
140 Commonwealth Ave.
Chestnut Hill, MA 02467
Tel: 617-552-1762 Fax: 617-552-1750
http://www.bc.edu/crr

\begin{abstract}
* Donald Cox is a professor of economics at Boston College. Beth J. Soldo is a professor of sociology at the University of Pennsylvania. The research reported herein was performed pursuant to a grant from the U.S. Social Security Administration (SSA) to the Center for Retirement Research at Boston College (CRR). The opinions and conclusions are solely those of the authors and should not be construed as representing the opinions or policy of the SSA or any agency of the Federal Government or of the CRR. Soldo also acknowledges support from NIA, and both authors acknowledge the contribution of Eileen Siegler who coauthored the HRS 2000 Module 5 with Soldo.
\end{abstract}

(C) 2004, by Donald Cox and Beth J. Soldo. All rights reserved. Short sections of text, not to exceed two paragraphs, may be quoted without explicit permission provided that full credit, including $@$ notice, is given to the source. 


\section{About the Center for Retirement Research}

The Center for Retirement Research at Boston College, part of a consortium that includes parallel centers at the University of Michigan and the National Bureau of Economic Research, was established in 1998 through a grant from the Social Security Administration. The goals of the Center are to promote research on retirement issues, to transmit new findings to the policy community and the public, to help train new scholars, and to broaden access to valuable data sources. Through these initiatives, the Center hopes to forge a strong link between the academic and policy communities around an issue of critical importance to the nation's future.

\section{Center for Retirement Research at Boston College}

550 Fulton Hall

140 Commonwealth Ave.

Chestnut Hill, MA 02467

phone: 617-552-1762 fax: 617-552-1750

e-mail: crr@bc.edu

http://www.bc.edu/crr

Affiliated Institutions:

American Enterprise Institute

The Brookings Institution

Massachusetts Institute of Technology

Syracuse University

Urban Institute 


\begin{abstract}
When adult children provide care for their aging parents, they often do so at great expense to themselves incurring psychic, monetary, emotional, and even physical costs, in conjunction with care that is labor intensive and, at the extreme, unrelenting. While the nature of parent care and the profile of care giving children are well described in the literatures of the social sciences, we still lack insight into why adult children undertake parent care without compensation or compulsion. In this paper, we adopt a novel, direct-question approach using newly available data from a special module fielded in the 2000 Health and Retirement Study that included questions on motivations for, and concerns with, the provision of familial assistance. We discover several new things about the provision of care in families. Transfers are not always provided free of pressure from other family members, for example, and familial norms of obligations and traditions appear to matter for many respondents. These findings suggest that the standard set of economic considerations - utility interdependence, budget constraints, exchange, and the like - are insufficient for a complete understanding of private transfer behavior. Though one must always be skeptical about reading too much into what people say about why they do the things they do (or think they will do) we nonetheless conclude that "point-blank" questions offer, at the very least, a worthwhile complement to the more conventional methods for unraveling motivations for private, intergenerational transfers.
\end{abstract}




\section{Introduction}

When adult children provide care for their aging parents, they often do so at great expense to themselves incurring psychic, monetary (e.g. foregone wages or promotions or delayed pension vesting), emotional, and even physical costs, in conjunction with care that is labor intensive and, at the extreme, unrelenting. While the nature of parent care and the profile of care giving children are well described in the literatures of the social sciences, we still lack insight into why adult children undertake parent care without compensation or compulsion. Are children caring for elderly parents motivated by altruism, guilt, obligation, or gratitude? Alternatively, intergenerational transfers from adult child to parent may be strategic (e.g., in anticipation of a larger bequest), dictated by family norms or traditions, or recognized as an opportunity to enhance self-esteem through family recognition, or a non-discernable mix of motives poorly captured by any one theory or discipline. Both economics and sociology acknowledge the importance of closing the gap, but for very different reasons. Economic theory, for example, focuses on a wide range of conceivable interactions between public and private transfers, i.e. public transfers may supplant or stimulate private transfers, depending on the motivation of the private donor. Despite the importance of motivations for private transfers, economic analyses are limited largely because of the dominance of the behavioral approach in which motivation is inferred from direct observation of choices made. In addition, "costs" are measured with only a monetary metric. In contrast, sociologists focus on intergenerational transfers for the insights they provide into how social bonds and networks are forged and maintained. In this paper we take a very different approach to those that dominate either mainstream economics or sociology. We adopt a novel, direct question approach using newly available data from a special module fielded in the 2000 Health and Retirement Study that included questions on motivations for, and concerns with, the provision of familial assistance. Our (deliberately) simple 
description of the data reveals abundant new information about the motivation for private transfers. Transfers are not always provided free of pressure from other family members, for example, and familial norms of obligations and traditions appear to matter for many respondents. These findings suggest that the standard set of economic considerations—utility interdependence, budget constraints, exchange, and the like-are insufficient for a complete understanding of private transfer behavior. These differences are consistent with prior research findings that demonstrate, for example, that women are far more likely to provide care and take seriously family obligations. Past experience in the provision of financial help and care matters as well, sometimes in intriguingly anomalous ways. Though one must always be skeptical about reading too much into what people say about why they do the things they do (or think they will do) we nonetheless conclude that "point-blank" questions offer, at the very least, a worthwhile complement to the more conventional methods for unraveling motivations for private, intergenerational transfers.

Economic research typically seeks to infer someone's underlying motivation from his or her actions. This indirect, "revealed preference" approach contrasts with a more straight forward method in which questions are asked to directly elicit from respondents their own insights into why they make certain choices, including the choice of doing nothing. By listening to what respondents say, there is the potential for incorporating nuance, subtlety, and a range of motives that are difficult to accommodate in the standard framework of economics. While sociologists, and especially anthropologists and psychologists, especially those who focus on personality, are far more accepting of a direct approach, their methods are not part of the analytic fabric of economics and are commonly denigrated by economists. Notwithstanding the considerable virtues of mainstream economic methods, we depart radically from the indirect "revealed-preference" approach in favor of a direct, "point-blank" approach, which queries survey respondents with blunt, straightforward questions concerning their reasons for providing familial transfers. Our data are from an 
experimental module, "Benevolence and Obligation", from the 2000 Health and Retirement Study (HRS). Many of the questions in this module reflect a more psychological perspective on understanding motivation, such as the psychic reward of recognition for helping a parent or the self assessment that one is better suited by temperament to care giving than are other potential caregivers, particularly siblings. Accordingly, our own methods are exceedingly simple; we let the data do the talking by reporting simple descriptive results.

Of course, whether the data generated by a direct, "point-blank" approach are credible is an important, but open, question. The literatures on survey design, field anthropology, and psychology suggest any number of reasons to be suspicious of responses to direct questions about motivation or sentiment. But we think that the best starting approach to point-blank questions is to give respondents the benefit of the doubt. Indeed, accepting responses at face-value is our (perhaps heroically naive) “identifying assumption.” But this paper is a first step in assessing the validity and reliability of the data we report on below. Using the rich family data contained in HRS, it will be possible in subsequent analyses to assess the predictive and construct validity of the derived measures we describe below.

\section{Disciplinary Perspectives on Transfer Motives}

Understanding why adult children undertake care giving for an elderly parent is but one aspect of research on intergenerational family transfers to which both economics and sociology have made important contributions. For the most part both disciplines generally accept a micro analytic framework that acknowledges: (i) the exigencies of potential recipients and the resources of possible donors' (ii) resource

\footnotetext{
${ }^{1}$ Modules, usually numbering about 10 in each HRS survey year, are randomly assigned to non-proxy respondents who consent to respond to 3-4 minutes of additional questions. Because respondents who completed their core interviews by proxy are systematically excluded from participating in the experimental modules, as are self-respondents who refuse, perhaps because of fatigue after a long interview, Module respondents are implicitly self-selected for good health and high cognitive capacity. Thus, module respondents are usually younger than HRS respondents as a whole.
} 
flows, both horizontally, e.g., sib to sib, and vertically in both directions ${ }^{2}$, and (iii) the fungibility of the basic behavioral currencies of intergenerational transfers, care hours, space, and financial assistance, with the potential to substitute one for another (Soldo and Freedman 1994). But most prior research has focused on simple exchanges from a single donor to a given recipient in a single currency at a point in time. The early convention of focusing only on dyadic exchanges is gradually yielding to a new tradition which understands recipient (or donor) selection from a pool of all possible recipients (or donors). Several panel surveys, including the Health and Retirement Study (HRS), are now routinely collecting the data needed to estimate such models ${ }^{3}$. These more complex and realistic models can be used to describe how a given donor selects a recipient from the pool of possible recipients or how a given helper is recruited from the pool of possible donors. The former issue is fundamentally a multi-generational resource allocation problem (e.g., Kuo and Hauser 1996; Soldo, et al.1999; McGarry and Schoeni 1997; Borsch-Supan et al. 1992) while the latter is a division of labor problem among multiple possible donors (e.g., Stern 1995; Wolf et al. 1997; Henretta et al. 1997). But data sets linking individual kin attributes to individual transfer behaviors allow for estimating the probability of a specific donor helping a specific recipient, given indicators of recipient need, donor resources, and attributes of other members of the donor pool. In this paper, we begin an assessment of whether direct motivational and personality indicators are important, but omitted, covariates in models of individual involvement in transfer streams (Hochguertel and Ohlsson 2000).

Economic Perspectives. Economic theories of intergenerational transfers are primarily concerned with donor motivation. In a basic economic model of exchange, the donor is the sole decision maker and is

\footnotetext{
${ }^{2}$ For example, from a mid-life parent to an adult child (e.g., Rosenzweig and Wolpin 1994), from a middle-aged child to a frail parent (e.g., Stern 1995: Henretta et al. 1997; Wolf et al.1997); or from an late life parent to a child or grandchild (McGarry and Schoeni 1997), as well as from a parent to young child (e.g., Duncan et al. 1998)

${ }^{3}$ In addition to the Health and Retirement Study (HRS), other sources of panel data on transfer streams are the National Long-term Care Study (NLTCS), the long-standing Panel Study of Income Dynamics (PSID), and the National Survey of Families and Households (NSFH).
} 
assumed to be selfish, choosing to assist a relative only as part of a "quid-pro-quo" arrangement (Bernheim, Shleifer and Summers 1985, Cox 1987, Altonji et al. 1992). A donor makes a choice about whether to provide assistance, and how much assistance to provide, based on maximizing his/her utility function, or wellbeing, subject to a budget constraint. Because financial transfers are usually of interest to economists, exchange models can be understood in terms of the donor "purchasing" services or behaviors of value to him/her. Economic exchange theory anticipates a negative correlation between the probability of a donor making a transfer to a given recipient and the recipient's financial resources; however, the theory makes no predictions as to the sign on the correlation between the amount received and the wealth of the recipient. Repayment can take the form of an implicit annuity contract to guard against financial loss (Laitner 1997), a claim on shared housing in the future, proximity of a donor parent to an adult child later in life (Tomassini et al. 2001), or a bequest (Bernheim 2000). By incorporating notions of "bargaining," exchange models allow both donor and recipient to be party to the decision-making process (Pezzin and Schone 1999a) and consideration is given to the resources of both. However, when economic exchange models are configured, they assume that the recipient enters into a repayment compact with the donor.

Economists contrast the exchange motive with altruism. Altruism implies that a donor provides resources, not because he/she expects repayment, but because the donor cares about the well-being of the recipient. Models of altruism infer donor motivation in terms of the effect of the transfer on the financial resources of the recipient.

Economists have only recently begun to consider the mechanisms which sustain intergenerational transfer systems. In economies with poorly developed capital markets (such as those in Mexico, Italy, and SE Asia), family transfer systems are important for ensuring against loss, providing loans, and accumulating savings (Frankenberg et al. 2002). In such economies, or in financially disadvantaged segments within these 
populations, recipients who default on an exchange transfer incur a stigma that reduces the probability of receiving subsequent transfers, even from others in the same family or network. Cox et al. (1998) suggest that "loyalty training" within a family [emphasis added] need not be assumed to sustain intergenerational transfers. Rather, "other emotions such as guilt or feelings of obligation may dwarf loyalty" ${ }^{4}$ Other economists have speculated that donors persist because of the "warm glow," or the unobserved psychological reward, a donor experiences in assisting others, especially children (Sober and Wilson 1998). Cox and Stark (1996) also have suggested that demonstration, or behavioral imitation, is an effective mechanism by which children come to value family transfers, e.g., by observing parents helping a grandparent. Elsewhere, Stark (1995) argues that even when cultural or genetic forces prejudice cooperation, altruism can prevail because individuals are more likely to interact with others who share this sentiment, such as siblings.

Sociological Perspectives. Because of their interest in small group structures, sociologists maintain an interest in intergenerational family transfers, regardless of their magnitude, direction, currency, or consequences for donor or recipient. Transfers do not simply redistribute resources across generations of a family, transfers strengthen social bonds between donor and recipient, promote family cohesion, and strengthen intergenerational links of responsibility and obligation. Transfers need not be directly observed to reinforce social bonds among kin. The telling of family stories may school subsequent generations in the lessons of family obligation. Particularly, long shadows over generations of a family may be cast by a mother's recounting of living with her grandmother as a child. A family history of intergenerational exchanges creates expectations of receiving and providing assistance at various points in the life-cycle for sequential generations of the family.

\footnotetext{
${ }^{4}$ Similarly Curran (2002) suggests that kin who shrink from intergenerational obligations may face "severe accountability sanctions" from other kin.
} 
Whereas economists distinguish among transfers based on the inferred motivation of the donor, sociologists consider how transfers affect social bonds. Enforcing this system of self-interest is the desire of both donor and recipient to continue receiving transfers. The family, as a small group, reinforces reciprocity by the mutual dependence of kin in activities, interactions, and sentiment. Non-reciprocity endangers social bonds of value to the recipient. Failure to reciprocate also is thought to reduce the status of recipient within the small group. Blau (1964) has argued that social and economic exchanges are similar in many respects although repayment options are often poorly defined in social theory. In their simplest form, dyadic (or restricted) exchanges (A to $\mathrm{B} ; \mathrm{B}$ to $\mathrm{A}$ ) are of interest to sociologists only to the extent that a delayed quid pro quo requires higher levels of trust and stronger social bonds than more immediate reciprocity. Beginning with the work of Levi-Strauss (1969), and continuing with modifications up to the current work of Molm and Cook (1995), Bearman (1997), and Lawler et al. (2000), sociologists have explored the implications and utility of "generalized exchange" theory. Generalized exchange requires a minimum of three participants who engage in two unilateral exchanges which satisfy the condition of indirect, or serial, reciprocity (A to B; B to C). Note that here generalized exchange consists of two distinct dyadic exchanges, either of which could be misinterpreted if not located in a broad family context. Bearman (1997) describes intricate chains of generalized exchange found in small, closed populations, but economists Ribar and Wilhelm (2000) describe more realistic exchange systems combining both simple one-way restricted exchanges and generalized exchanges. Assume we observe three generations of a family over several periods. At $T_{1}$ an adult child (G2) lives with her mother from the first generation (G1). The G1 parent may incur an obligation to repay her daughter, perhaps with a bequest, or the mother-daughter co-residence may fulfill the daughter's obligation to reciprocate for an earlier transfer. In either case, the G3 grandchild may assume an obligation to assist his/her own G2 parent at $T_{2}$. The conditions of generalized exchange also would be satisfied if the child of a G2 sib 
(say, for example, a G3 niece) observes the help her G2 aunt provided her G1 grandmother, which in turn strengthens the niece's resolve to assist her own mother. Generalized exchange also seems to provide a good fit to the intricacies of human and social capital exchanges linking generations. Generalized exchange theory anticipates that families (or other small networks) will differ in their collective transfer behaviors because of differences in embedded norms of caring and obligation.

Compared to the economic theory of exchange, in which a donor expects repayment from a specific recipient, generalized exchange appears quite risky to the initial donor because reciprocity cannot be guaranteed. Transfers are unilateral as the initial donor need not observe or even know when his or her recipient reciprocates by assisting others in the family. While generalized exchange seems to be a regular feature of life (e.g., academic reviews of manuscripts), the potential for "free-riding" is an inherent social dilemma. How might the risk of free-riding be checked? Theoretical answers have invoked notions of pure altruism, rational choice, or game theory, in which individuals provide unilateral resources if and when such behavior conveys benefit, such as altruistic punishment, recently discussed by Fehr and Gachter (2002).

Researchers would not expect to observe or account for all links in a generalized chain of transfers. Nonetheless, generalized exchange may have special relevance in populations such as our own where family structures are primarily vertical, with few lateral extensions, and large proportions of families contain three or four generations (Wolf 1994). Generalized exchange theory is not sufficiently developed to the point where it can replace more standard explanations of transfers. It is, for example, uninformative about the criteria a donor uses in reciprocating for an earlier transfer received. It may well be that the dynamics of individual motivation for reciprocating for a prior transfer to a third party rather than the original donor are rooted in sentiment and psychological factors. 
Standard covariates in transfer models. It is useful to consider findings from prior research on how attributes of potential donors affect their transfer behavior. In this section we focus only on those factors for which there is near consensus on their importance. In problems of how siblings allocate time to assist their frail mother, her condition, as well as the cumulative family history of assisting one another, are obvious considerations, as are family size and composition. Other things being equal, kin in larger families are less likely than those from smaller families to either receive help from a parent (McGarry and Schoeni 1995 and 1997) or to provide assistance to a parent (Spitz and Logan 1990). Wolf and Soldo (1990) and Wolf et al (1997), among others, show that the intensity of parental care varies directly with family size. But sociologists Steelman and colleagues (2002) have recently called for a more careful consideration of the mechanisms by which family composition confers benefits and disadvantages, beyond the inverse correlation of family size and family resources. For several reasons, family size and structure may indeed do more than arithmetically adjust the odds of giving or receiving help. First, children are not interchangeable targets either for attracting parental resources (Behrman et al. 1994) or, later in life, for assisting elderly parents. Women, for example, are not only far more likely to provide hands-on care for children at any age, but also in mid-life to care for their elderly parents (Soldo et al. 1999). Women are typically seen as more suitable for doing "caring work" perhaps reflecting the relative value of their time in the market place, or the stronger or earlier socialization of women into the role of "kin keepers" as Hagestad (1992) speculates. Second, with the completion of fertility, the parity rankings of offspring are fixed within a family as are parent-child and sib-to-sib age differences. Ordinal rankings, among other factors, may affect the human capital investments parents make in their individual children (Hauser and Kuo 1997). But absolute age differences between parents and child also affect whether the overlap in their subsequent life-cycle stages facilitate or discourage family transfers in either direction at key generational transitions such as parental widowhood, child divorce, or birth of grandchildren. 
Tightly spaced fertility, for example, may later curtail sizeable or equal parental investments in the human capital of offspring. Steelman et al. (2002), for example, argue that younger offspring reap greater economic benefits than older children both because their parents have greater financial resources later in life and fewer outstanding "fiduciary obligations" to older siblings. Later in their life cycle, the obligation to reciprocate for parental generosity may more strongly motivate younger children to assist.

Race and ethnicity also are important sources of between-family variance and a regular feature of intergenerational transfer models (Berry 2001a and b). Most often these variables function as meta-statistical controls for unobserved structural differences in family size, generational composition, family age distribution, and kin proximity. In addition, race and ethnicity are assumed to convey the effects of past economic hardships, resulting in low levels of financial resources, and reduced chances of offering or receiving family economic aid. Also, race and ethnicity also regularly proxy for a host of cultural features which "regulate the values and norms that regulate family relationships" (Johnson 2002:628).

Sociologic and economic perspectives on intergenerational transfers are increasingly informed by analyses which take into account attributes of potential donors and recipients as predictors and dyadic transfers of various types among extended family members as outcomes. Panel estimates of such models are far superior to those based on cross-sectional data because actual change in probable triggers, notably transitions in marital, health, or financial status, are observed within families rather than inferred from crossfamily differences. Of particular interest are studies concerned with why family transfer systems emerge and how they are nurtured. Theories of social exchange require efforts to understand why families differ in their shared orientation to intergenerational obligations or reciprocities. Often times fixed-effects models are interpreted as suggesting the power of "unobserved family heterogeneity" with respect to such within family differences. But to move the agenda on intergenerational transfers requires efforts in two areas: 1) developing 
and evaluating actual measures of collective family orientation such as those implied by the "demonstration" hypothesis and generalized exchange theory, and, 2) considering family transfers in dynamic models which incorporate both fixed and varying attributes of individuals and the family as a whole.

The Dataset and Sample. The information we use comes from a special module of the 2000 Wave (the fifth wave) of the Health and Retirement Study, called "Benevolence and Obligation," which queries respondents, in a rather direct manner, about how they see their role as familial helpers, and what their concerns and motivations are for providing help to relatives.

Like all experimental modules in the HRS, this one is a random subset of all core self interviews in a given wave. In 2000, about one out of 12 households were assigned "Benevolence and Obligation," and only one person from the household answered the module questions. ${ }^{5}$ Respondents whose core interview was completed by a proxy are not eligible for participation in the HRS experimental modules. The sample characteristics for the module we consider below are shown in Table 1 below.

Since 1998, the HRS consists of respondents from four distinct birth cohorts: ( $i$ ) AHEAD respondents from the short-lived study of the Asset and Health Dynamics of the Oldest Old who were born prior to 1923; (ii) CODA (Children of the Depression) respondents born between 1924-1930; (iii) the original HRS cohort of 1931-1941; and (iv) the cohort of War Babies, born between 1942 and 1947. ${ }^{6}$ At the time of wave 5 in 2000, the average ages of each cohort was AHEAD, 82; CODA, 74; HRS, 64, and War Babies, 55. Sixty percent of our sample are women.

\footnotetext{
${ }^{5}$ There were 11 other special modules in the 2000 HRS, including modules about economic and social altruism. No respondent answers more than one module.

${ }^{6}$ The abbreviation HRS is potentially confusing because it could stand for either one of two things: the Health and Retirement Study, which encompasses all four cohorts, and the Health and Retirement Survey, which is a distinct cohort within the Health and Retirement Study.
} 
Table 1

HRS 2000: Select Characteristics of the complete sample and Module 5

\section{HRS 2000}

Total \# of Wave 5 Respondents

19,580

Total \# of Wave 5 Households

13,214

MODULE 5. HRS 2000

$\begin{array}{ll}\text { Number } & \text { Percent } \\ 1,133 & 100.00 \%\end{array}$

Cohort of Module Respondent

AHEAD Respondents (born before 1924)

252

22.24

CODA Respondents (1924-1930)

135

11.92

Original HRS Respondents (1931-1941)

590

52.07

War Babies Respondents (1942-1947)

156

13.77

Sex of Module Respondents

Women

675

$100.00 \%$

Men

458

59.58

40.42

Source: Authors' tabulations from HRS 2000.

Point-Blank Questions. Because we rely exclusively on responses to questions in the module, the wording of the module questions is especially important. The Appendix to this paper shows the question wording and the marginal frequencies from the on-line HRS documentation. Our first set of figures describes these code counts, in pie-chart form, for the series of questions about how respondents think of themselves in their roles as family helpers.

What do these figures tell us? We summarize the salient findings below.

1. "Point-blank" questions clearly present a potential minefield of misrepresentations, exaggerations, biases, and framing effects.

1-a. There is evidence of self-serving bias. 
People tend to look at themselves in a positive light, indicating a high opinion of their generosity to family members. Just about all respondents (97 percent), for example, thinks of themselves as "trying to be thoughtful" (Figure 1-c) or "charitable" (84 percent, Figure 1-e). Findings such as these are consistent with abundant existing evidence on self-serving biases. ${ }^{7}$

1-b. Despite the specter of self-serving bias, in some instances, non-trivial percentages of respondents characterize themselves in less-than-positive ways.

When given the statement "Some people think I'm selfish and egotistical," for example, only 22 percent of respondents perceived that this statement applied to them (Figure 1-a). That is, they either agreed (10 percent) or chose "neutral" as their response (12 percent). We think that, in light of tendencies toward self-praise, the choice of "neutral" for a negative-sounding statement might well be revealing about respondent self image—-hence, our focus on percentages that "did not disagree" with the statement. More generally, one thing that self-serving bias could do is to render negative, and even neutral, responses that are much more noteworthy; something must be going on to prompt responses to go against the self-serving grain.

1-c. Wording matters a lot.

In Figure 2-a, 84 percent of the respondents agreed (and only 2 percent disagreed) with the statement "I want to be remembered as the one who was always there when someone in the family needed help." But in the very next statement in the module, nearly half (46 percent) disagreed with "I'm hurt if I do something for others and it isn't recognized." This seems to imply that a lot of people want to be remembered but are not concerned if they are not. This discrepancy is not necessarily illogical, but nonetheless the thrust of these two statements is somewhat similar, except for framing. In the first, being remembered as 'always there' appears

\footnotetext{
${ }^{7}$ For recent summaries, see, for example, discussions in Babcock and Loewenstein (1997), Camerer (2003), and Santos-Pinto (2003). The studies cited therein point to a marked "Lake Wobegon" effect—where a large majority describe themselves as above average - for a wide variety of traits, including: driving ability, athletic ability, teaching ability, sense of humor, and the ability to get along with others. Lerner, et. al. (1991) find similar biases in respondent characterizations of their propensity to provide care to the elderly.
} 
to be viewed as a welcome accolade, yet if this accolade is not forthcoming it may not be seen as an important issue, perhaps drawing self-satisfaction from knowing that one did what was right is sufficient reward. It is easy to see how misleading impressions about motivation could be if direct questions adhere to only a single axis. Framing issues imply that point-blank questions must be treated with caution and skepticism.

2. Despite these obvious hazards, we think that these questions can nonetheless be informative, and they might even help settle some thorny conceptual issues about familial transfers in an efficiently straightforward manner. We illustrate with three examples below.

2-a. Example 1-potential conflict within the family.

Are families efficient? In the parlance of economic theorists, do they reach Pareto Optimal equilibria? Early models of family behavior, such as the altruistic model of Becker (1974), or the Nash-bargaining models of McElroy and Horney (1981) and Manser and Brown (1980), contained efficient solutions. Indeed, in the case of Becker's model, we might even apply the term "hyper-efficient" to describe the equilibrium, because it could well prove impervious to the mischief of misanthropic progeny, according to Becker's famous "Rotten Kid" theorem. Why? Because even a rational misanthrope will refrain from biting the hand that feeds him or her. In Becker's model, the family doesn't just attain efficiency, it can actually breed efficiency via an infectious pseudo-altruism that can transform a filial misfit into a full member of the familial network with all the rights and privileges that status accords.

The models above were generalized by Chiappori (1988) who analyzed family behavior under weaker assumptions. It was Pareto Optimality that remained the key assumption left standing after he stripped away the rather special attributes of the above approaches (such as Becker's dominant, altruist decision maker, McElroy and Horney's bargaining assumptions). The idea is appealing to economists, since it is hard to reconcile waste with rationality. 
Nonetheless, challenges to the Pareto Optimality assumption have arisen in several contexts. Robert Trivers' (1985) theory of parent-child conflict predicts that biological exigencies create a backdrop for nasty child behavior: my mother likes my sister and me equally and wants us to share, but I like myself better than I like my sister, which impels me to make a grab for more than my fair share. Marxist-feminist approaches (e.g., Folbre 1986) posit that the family could be an arena of exploitation where weaker persons are exploited by their more powerful relatives. Lundberg and Pollack (1993) cast marriage as a non-cooperative game, in which disaffected spouses might retreat into "separate spheres," a Pareto inferior equilibrium akin to the tragedy of the commons, in which each spouse defects by not investing enough in the marriage, but doesn't actually leave the marriage. Becker himself, in a 1993 paper, posits a model of "preference formation" in which one family member might make another member's life miserable in an attempt to extort resources from them. Udry (1996) rejects the Pareto Optimality hypothesis in a study of West African farming households, and argues that the prevailing approaches that assume efficient outcomes should give way to those that admit the possibility of waste.

But testing for wasteful behavior is much easier said than done, and Udry's paper, which is in the traditional "revealed preference" tradition, is testament to that. Finding evidence for waste, particularly when economic logic provides little guidance for systematic analysis of waste, is a daunting prospect. In another context, Kennan (1986) makes a related argument in the context of economic analysis of strikes, elucidating what he calls the "Hicks Paradox": Imagine someone invents a theory that predicts when and for how long a strike will occur, and what the outcome will be. Seeing how strikes are wasteful, shouldn't the interested parties use this information to bypass the strike and proceed immediately to the outcome? But in so doing, do they not cause the theory to cease to hold? 
We argue that a way out of this bind is to apply the point-blank approach to the null hypothesis of Pareto Optimality in the family. The null is important, and economic logic predicts that forces work in its favor, so that finding any evidence of waste (regardless of how or why it happens) is potentially noteworthy. Consider, then, the following statements:

- "My immediate family sometimes pressures me to do more than I want to do for them."

- "I sometimes have to ask over and over again to get my immediate family to help me."

Nearly a quarter did not disagree with the first statement (Figure 3-g) and nearly a fifth did not disagree with the second (Figure 3-h). The bottom line is that all is not necessarily well within the family, and these "point blank" findings perhaps pose a prima facie challenge to Pareto Optimality. ${ }^{8}$

\section{2-b. Example 2-The case of the "Mercenary Reciprocators."}

Figures 2-c and 2-d indicate a significant minority of what we might call "Mercenary Reciprocators": family members who scratch your back only if you scratch theirs. That is, they agree with (or at least do not disagree with) the idea of helping a family member only if that person has provided (or will provide) help in exchange.

The findings are relevant for the very large literature attempting to test altruistic versus exchange-related models of familial transfers. As is true of most other empirical work on the economics of the family, the most existing tests are of an indirect, "revealed-preference" nature, focusing on income effects predicted by the different theoretical models (e.g., Cox 1987, Altonji, Hayashi and Kotlikoff 1997).

\section{2-c. Example 3-Imitation, norms and tradition.}

Most models of familial transfers analyze the behavior of a generic "donor" toward a generic "recipient": a parent invests in a child, for example, or an adult child cares for her elderly parent. Rarely do third-party

\footnotetext{
${ }^{8}$ These responses also provide additional evidence, consistent with earlier arguments, of how critical the wording of statements can be. Eighteen percent agree they sometimes feel pressured to provide more familial help than they want to, but only three percent agree that they resent having to help family members.
} 
family members enter the scene ${ }^{9}$. Might the standard two-party modeling framework be as narrow as the theory of Generalized Exchange suggests?

For instance, suppose, as in Cox and Stark (1998, 2003), a woman cares for her frail elderly mother partly in the hope that her son will imitate her caring behavior once she needs such care herself. Or suppose that part of the impetus for leaving a bequest to one's children is to carry on a family tradition of giving (Cox and Stark 2004). Such examples point up the possibility that familial transfers are not determined solely by behavior within donor-recipient dyads. Norms might matter. As an adult child with a sick elderly parent, I might wonder exactly how much I am supposed to do for them. I might be interested in what they did for their own parents, for example. In making transfers to my children, I might have some idea of what a parent is "supposed" to do, based on what I saw my own parents do.

The point-blank evidence from Figure 4 indicates that these kinds of considerations matter for many respondents in the module:

- Fifty-eight percent agreed with "I do (did) for my parents what they did for me" (Figure 4-a).

- Forty-six percent agreed with "I do (did) for my parents what they did for their parents" (Figure 4-b).

- Sixty-five percent agreed with "I do for my kids what my parents did for me" (Figure 4-c).

The verdict is far from unanimous, and many respondents disagreed with these statements, but Figure 4 makes one thing clear: It is very likely that norms of imitation and obligation matter, so that models of family behavior should move beyond the simple dyadic approach in order to introduce these considerations. Fortunately the full array of HRS family data can support such modeling efforts.

\footnotetext{
${ }^{9}$ Papers by Wolf and co-authors (1988, 1994, and 1997) are notable exceptions. In these papers each adult child is modeled as a distinct option for proving care or co-residence to an older parent or parent-in-law. Furthermore each adult child is assumed to observe the attributes of all others siblings, such as marital status, family size, or work hours, and take these into account in making their own but simultaneous offer of help.
} 
That said, we hasten to add that it is by no means clear that the evidence in Figure 4 settles the issue, even if we assume that respondents are being completely truthful. There remains the issue of what the responses really mean; whether they really have to do with norms or indicate some other behavior. For instance, when a respondent agrees that "I do for my kids what my parents did for me," what is he or she really saying? True, the respondent might mean that he is trying to copy his parents' behavior, to carry on a tradition, but not necessarily. The import of the statement could instead be something like this: "Yeah, as it turns out, I'm going to wind up doing for my kids what my parents did for me, though I really didn't have any deliberate intention of doing so. It's just that they had the money to send me to college, and I also happen to have the money to be able to send my own kids to college. It's all about being able to afford it rather than wanting to carry on any kind of tradition." In other words, a dyadic model could generate the result we see, simply because budgets might be correlated across generations. Moreover, the three statements above don't even broach the issue of intention— they are consistent with unintentional, maybe spurious, effects.

One statement does seem to broach the issue of willful behavior, though, and that is the last question about parental effects, depicted in Figure 4-d, which says “I don't (didn't) do for my parents what I saw my parents do for their parents." What makes this statement different is the phrase "what I saw my parents do." One possible label to attach to those who agreed with the statement is "willful renegades": they saw their personal history and made a decision not to repeat it. Whatever we might wish to label them, one thing is certain, they are a minority (11 percent).

Splitting the Sample, Part I-Gender Differences. Who is more likely to be more considerate and giving to family members, a woman or a man? If you believe the responses to "point-blank" questions, the answer would be "women." Let's start with negative characterizations, like "Some people think I'm selfish and egotistical": 14 percent of the men concurred with this statement, compared to 8 percent of the women (Figure 
5). Similar disparities exist for responses to "Some people think of me as cold and calculating," and "I'm not known for my generosity." In each, the differences are statistically significant at any popular level, and they are large. For example, twice as large a percentage of men agreed about being thought of as "cold and calculating" (10 percent as opposed to 5 percent for women).

These results are qualitatively consistent with what we know about sex differences in the propensity to care for relatives. To a first approximation, for example, daughters provide roughly twice as many hours of help to elderly parents as do men (Wolf et al. 1997) and those differentials are not solely due to differences in incentives, such as wages. This gender differential maintains even after controlling for such factors in other models (e.g., Tomes 1981; Leigh 1982). ${ }^{10}$ Despite the consistency of negative sentiments with well-described behavioral differences in family care (a weak form of construct validity), the tendency of women to reject these statements may simply reflect gendered socialization (Folbre 1986). When we examine gender differences in agreement with positive self-descriptors, comparable differences are observed. Women consistently characterize themselves as "nicer" than their male counterparts (Figure 6), but the differences are not large and, for some items, not statistically significant.

One perspective on Figures 5 and 6 is that the point blank questions on which they are based add little value to our existing understanding of gender differentials in the provision of familial help. After all, there is abundant existing evidence from behavior-based studies of gender differences in providing care or financial support to kin and finding a qualitative concordance with point-blank questions is perhaps not all that noteworthy. In particular, the quantitative results at least from Figure 6 do not seem all that informative since these weak differentials are consistent with self-serving biases and gendered social roles. The final test of the

\footnotetext{
${ }^{10}$ They are also consistent with at least some experimental findings. Andreoni and Vesterlund (2001), for example, find that women outdo men in their propensity for relatively high-stakes acts of altruism (though the pattern is reversed for smaller altruistic acts).
} 
worth of the point-blank questions, such as those in Module 5, must wait for estimation of within and between models of family transfers.

Nonetheless we observe comparable differentials in response to more subtle questions, such as the need for recognition or reciprocity. The first two panels in Figure 7 show gender differences in each, with higher percentages of men acknowledging that they require both recognition and reciprocation. Thirty-two percent of men said they would be hurt if their help were not recognized, compared to 26 percent of the women. About one in five men—compared to one in six women—failed to dismiss the statement that "I only help relatives and friends who've helped me in the past."11

The last two panels of Figure 7 reinforce the familiar stereotype about how men and women focus on differing currencies of familial help. A much higher percentage of men compared to women agreed with the statement that "In my family, I'm the one who's best able financially to help others" -44 percent versus 25 percent, the largest gender difference of any of those reported here. Conversely, women are more likely than men to tout their emotional capabilities. Fifty-one percent of women, compared with 44 percent of men, agreed that "In my family, I'm the one who's best able to help others because of my temperament." Again, though, we must ask ourselves how large the value added is for these last two questions, since we already have a lot of information, from surveys of what people do, that are consistent with these responses. In addition, there may not be appreciable value in the items on the financial and emotional qualifications of potential donors in families in which there are no sex differences among the adult children.

Figure 8 displays differences in the propensities of men and women to be susceptible to the parental influences discussed above. In this Figure, we define as a "reciprocator" a respondent who concurs with the

\footnotetext{
${ }^{11}$ Note the difference in wording here; with this question we combined agreeing with being neutral. A differential exists if we recast the figure in terms of just agreeing, but it is narrower, and only marginally statistically significant. Further, our results only pertain to the question about reciprocating help provided in the past. There is a similar differential for the question about future help, but, again it is smaller and insignificant.
} 
statement that he/she does for parents what they did for him/her; an "imitator" is one who does for parents what they did for theirs (the respondent's grandparents); a "traditionalist" is one who does for own children what his/her parents did for him/her; and, a "contrarian" as one who reports that he/she does not do for own parents as they did he for his/her grandparents. The bars in Figure 8 show the percentages agreeing with each of the four items. Men appear more susceptible to parental influences than women, but the male-female difference is statistically significant only for the propensity to be a traditionalist ( 54 of men versus 48 percent of women agreeing).

In summary, none of the gender differences described in this section is surprising. But consistency does not, in and of itself, validate the utility of point-blank questions relative to repeated observations of donor behavior in the context of the family option set for parental care.

Splitting the Sample, Part II-Age Differences. In this section we consider response patterns by age. We divide the sample by birth cohort as defined by the HRS. We group respondents who by birth year belong to the AHEAD or CODA cohorts (aged 70+ in 2000) and collectively label these respondents as relatively older. Respondents born between 1931 and 1947, i.e. the original HRS cohort and the cohort of War Babies, we refer to as relatively younger (ages 53 to 69 in 2000). These two cohorts are unequal in sample size and the span of birth years covered. We also use the term "age effects" - advisedly we might well replace it with "cohort effects" or "survivorship effects," which are behavioral distinct concepts but confounded with age.

With these caveats in mind, we first consider differences by gender within broad age groups with respect to personality differences in Figure 9. Age differences are consistently more pronounced for man than women. Older male respondents were twice as likely as younger men to agree with statements that they were sometimes thought of as "selfish and egotistical" than among younger male respondents. Likewise, older men 
were more apt to characterize the way they are seen by others as "cold and calculating" and "not known for my generosity," though the age differences are smaller and not statistically significant. Older men also are more likely than comparably aged women to describe themselves in unflattering terms, although older women also are more likely to use these terms to describe themselves than younger women.

There are at least three possible explanations of these findings. The first is that they convey some sort of sample composition effect, by which those who survive or remain sufficiently lucid to provide a selfinterview in the HRS core are on average-for lack of a better word-“grumpier." A second possibility is that the age-gender differences shown in Figure 9 reflect true age differences in the sense that with age, social skills erode or decay in value. Finally there is the possibility of cohort effects, which we find less compelling because relatively younger respondents came of age in times of greater competition $\mathrm{n}$ marriage and job markets among others. Note, however, that younger women, who are more likely to had had sustained spells of paid work, were more likely than older women to acknowledge that they were sometimes seen as calculating. Whatever the explanation (and we think this is something worthy of more exacting investigation) these cohort differences are smaller, and statistically insignificant, among women.

Another place where age differences may be manifest is with respect to reciprocity, if only because with age, respondents accumulate more person-years of exposure to providing or receiving assistance. A higher proportion of older respondents, for example, did not dispute statements such as "I only help relatives and friend who've helped me in the past." Figure 10 shows, for example, that nearly one third of male respondents either agreed or gave a neutral response to this question, compared with 19 percent of younger male respondents. Though the percentages are lower for women, cohort differences maintain for them as well, although concerns for past or future repayments for help given are less salient for women, regardless of age. 
One cohort effect that indicates gender differences is with respect to the need for recognition, as shown in Figure 11. Roughly the same percentages of male and female respondents from the younger cohort agreed that they would be hurt if their help were not recognized ( 29 and 28 percent, respectively) but older men are considerably more likely than comparably aged women to acknowledge the importance of recognition for helping deeds, 37 percent and 23 percent, respectively.

Figure 12 reveals another aspect of gender differences by age. Here we examine responses to the question if the respondent felt pressured to provide more help than they wanted. The percentage of women who either agreed with, or responded neutrally to, the statement "my immediate family sometimes pressures me to do more than I want to do for them" was 25 percent for younger-cohort women but only 14 percent for older-cohort women. The corresponding percentages for the men followed a similar pattern but were far less pronounced. It is not clear if respondents were responding to current circumstances or earlier ones. Hence, one possible reason for this gender difference may be unobserved rhythms of the life course. In mid-life women may be more vulnerable to competing claims from work, family life, and care needs of grandchildren and parents/parents-in-law. After age 70, women are less likely to be juggling such a range of competing demands as the demands themselves retreat or spouses and adult children come to recognize that the health or functional capacity of their wife/mother is degrading. It also may be that women tend to specialize in timerelated help, whereas men are more likely to provide monetary help. The ability to provide financial assistance may attenuate at a slower rate than the physical capacity, the latter being a prerequisite for providing time help. Splitting the Sample, Part III-Differences by earlier helping behavior. Consider two groups of respondents that can be identified in the HRS panel. The first contains those who have actually provided help to their parents at least once in the recent past, and the second contains respondents who have never provided such help. Which group would we expect to think that their family is more likely to see them in an unfavorable 
light? The answer, perhaps surprisingly, is sometimes the first group, those who actually provided help in the past. Figure 13 shows, for example, that 22 percent of the women respondents who provided help to their parents or in-laws sometime in the past 10 years agreed or were neutral in response to the statement that "Some people think I'm selfish and egotistical" compared to 14 percent of their non-helping counterparts. Likewise, 29 percent of the women in the group of helpers did not reject the statement that "I'm not known for my generosity" compared to 19 percent of the women in the group of non-helpers.

Before we attempt to speculate about why this might have occurred, additional sample restrictions need to be considered. First, our universe of respondents considered in Figure 13 is restricted to those in the HRS cohort who had at least one living parent at the time of the first wave of the survey. Approximately 400 women and 185 men meet this criterion. Furthermore we define help experience as providing at least one of the following to parents or in-laws: 100 or more hours of help with, in the words of the survey question, “...basic personal activities such as dressing, eating, and bathing,” or \$500 in financial assistance. A little over half of the women (204 out of 398) and about 40 percent of the men (72 out of 185) provided such help to parents or in-laws since the respondent's first HRS interview.

Why might those who have already provided help be more apt then non-helpers to characterize how they are seen by others in a more negative light? Venturing out on a Imb we speculate on the behavioral forces that could conceivably give rise to these seemingly odd results. Imagine that person A has never helped a parent or in-law, for reasons completely exogenous reasons-such as never having had to put her filial altruism to the test by, for example, assisting her mother-in-law with activities of daily living. Person B, on the other hand, is already a battle-hardened familial soldier who has, on more than one occasion, directly provided parental care. Perhaps "B" has learned, in the course of this experience, that her altruism, despite her best intentions, has its limits. Perhaps she has even been reminded by a frail parent that she isn't doing enough for 
them, regardless of the hours of help provided. On the other hand, perhaps a "battle-tested" individual has had more opportunity to learn about how needy family members might actually see them, and this feedback has dampened their notions of their own generosity and selflessness that they harbored before it was put to the test.

Part of the reason why we find ourselves so far out on the speculative limb is that, unlike comparisons involving age or gender differences, we are now splitting the sample by what is clearly an endogenous variable. Notwithstanding the minefield of potential biases we have created for ourselves here, think of what might be the simplest conceptual model possible. Imagine that some people are nice and others are not so nice, and that the nice people are more apt to do nice things and are more apt to characterize themselves as being seen as nice by others. In that very simple framework, splitting the sample according to whether people have indeed done something nice should have generated results that go in the opposite direction of the trends depicted in Figure 13. ${ }^{12}$

Since we have just about reached the speculative "point of no return," we will take the final step and bring our ruminations to their logical limits. Again suppose some people are nice and some are not so nice, and that people who view themselves as nice tend to do nice things, except that, in doing these things, much of their self-serving bias about how others see them gets destroyed in the process. Imagine too that this latter effect is quite strong — strong enough perhaps to overwhelm the initial and more ordinary positive correlation between being nice and viewing oneself as nice. One implication of this (admittedly exploratory) logic is that the correlation between how people see themselves and the help they actually provide will depend on whether that help has already been provided or whether it has yet to be provided. Those who have already provided

\footnotetext{
${ }^{12}$ For one of the questions, having to do with being seen as "cold and calculating," these results do appear to go in this direction but they are not statistically significant.
} 
help have had their altruism tested, so that their self-image has been taken down a peg; those who have not are still in the throes of self-serving bias, so that non-helpers see themselves in a better light than helpers. But among a sample of people who have not yet provided any help, we should still observe a positive relationship between being nice and viewing oneself as nice. Accordingly, for this group, today's positive self-image would be indicative of tomorrow's actual help provided.

Our last figure, Figure 14, considers just such a group: respondents who have not provided any help in the fifth wave (2000) or in earlier waves. We looked at the same set of variables as in Figure 13, but now we split the sample according to whether respondents provided any future help: specifically, whether they reported providing any help to their parents in the sixth wave (2002) of the HRS. Figure 14, unlike Figure 13, shows a positive relationship between thinking of one self positively and providing future help.

\section{Next Steps}

Because the data on respondents who participated in Module-5 (M-5) can be linked with their core data from their first observation to the most recent (self or proxy interview, or the next-of- kin interview for deceased respondents), HRS affords the opportunity to test some of the inferences we draw in this paper. All core interviews contain data on: $(i)$ the attributes of the individual siblings of the HRS respondent and the financial and care assistance each sib provides a parent ${ }^{13}$; (ii) previously unobserved spells of co-residence with a parent and the respondent and his/her siblings after leaving home but prior to the first interview with the HRS respondent were queried in 2002 and again in 2004 for new "Early Boomer" respondents, i.e., the cohort born 1948-1953; and, (iii) the attributes of individual children and the flow of resources and help to

\footnotetext{
${ }^{13}$ Respondent reports on the characteristics and transfer behavior of each individual sib continue until the death of the last parent or the death or loss of the HRS respondent.
} 
and from each adult child to the HRS respondent ${ }^{14}$, including for deceased respondents the distribution of bequests to individual children. In addition, in 2002 and 2004 (for new respondents) each respondent reported on whether as a minor child he/she lived with a grand-parent. In combination these data will allow us to:

- Evaluate the M-5 respondent's assessment of whether he/she is the best able to provide financial help in the context of earlier reports on each sib's education, home ownership, labor supply, household earnings, family size, and marital transitions;

- Consider whether prior transfer history colors self-perceptions of own generosity, helpfulness, or willingness to provide assistance "no matter what the costs" in terms of intensity of help given, number of helping spells; attributes of the recipient, e.g., mother vs. father, and nature of the donor's relation to the recipient, e.g., parent vs. parent-in-law or biologic vs. step-child.

- Correlate the extent to which pre- and post-2000 observations of transfers involving the M-5 respondent and three or more generations of his/her kin with self-reports of the saliency of reciprocity as motivation for assisting family;

- Assess the predictive validity of M-5 items in models of family transfers observed after 2000, net of conventional socio-demographic and economic predictors; and

- Determine if the M-5 point-blank questions provide added value compared with accumulating observations of prior exchanges given or received by M-5 respondents in fully specified models.

Pending a more thorough multivariate examination of the data from the 2000 Module-5, "Beneficence and Obligation", the findings we report in this paper are rightly deemed speculation, albeit interesting speculation, rather than conclusions per se.

\footnotetext{
${ }^{14}$ Any assistance given to or received from a grand-child is indexed to the child's parent, i.e., the adult child of the respondent.
} 


\section{REFERENCES}

Altonji, J.C., F. Hayashi, and L.J, Kotlikoff. 1992. Is the extended family altruistically linked? Direct tests using microdata. American Economic Review, 2(5):1177-98.

Altonji, Joseph G., Hayashi, Fumio, and Kotlikoff, Laurence J. "Parental Altruism and Inter Vivos Transfers: Theory and Evidence." Journal of Political Economy 105 (December 1997): 1121-1166.

Andreoni, James, and Vesterlund, Lise. "Which is the Fair Sex? Gender Differences in Altruism." Quarterly Journal of Economics, 116 (February 2001): 293-312.

Babcock, Linda and Loewenstein , George. "Explaining Bargaining Impasse: The Role of Self-Serving Biases." Journal of Economic Perspectives (Winter 1997), pp. 109-126.

Bearman, P. 1997. Generalized exchange. American Journal of Sociology 102: 1383-415.

Becker, Gary S. “A Theory of Social Interactions.” Journal of Political Economy 82 (November/December 1974): 1063-1093.

Behrman, J.R. 1997. Intrahousehold distribution and the family. Pp. 125-188 in Handbook of Population and Family Economics. Edited by M.R. Rosenzweig and O. Stark, Amsterdam: Elsevier.

Behrman, J. R., M. R. Rosenzweig, and P. Taubman, 1994, "Endowments and and the Allocation of Schooling in the Family and in the Marriage Market: The Twins Experiment," Journal of Political Economy 102:6 (December), 1131-1174.

Bernheim, B. Douglas, Shleifer, Andrei and Summers, Lawrence H. “The Strategic Bequest Motive.” Journal of Political Economy 93 (December 1985): 1045-1076.

Bernheim, B.D.2000.Bequests as signals: An explanation for the equal division puzzle, NBER Working Paper 7791.

Berry, B.M. 2001a. What explains race and ethnic differences in family transfers to adult children. PSC Research Report, Report No. 01-486. Ann Arbor MI: Population Studies Center.

Berry, B.M. 2001b.All that binds: Race, ethnicity, and why families support adult children. PSC Research Report, Report No. 01-487. Ann Arbor MI: Population Studies Center.

Blau, P. 1964. Exchange and Power in Social Life. NY: John Wiley \& Sons.

Borsch-Supan, A., J. Gokhale, L. J. Kotlikoff, and J. Morris. 1992. The provision of time to the elderly by their children. Pp. 109-134 in Topics in the Economics of Aging, D.A. Wise (ed.), Chicago: The University of Chicago Press. 
Byrne, D., M.S. Goeree, B. Heidemann, and S. Stern. 2000. Long-term care, home health care, and informal care. Mimeograph Department of Economics, University of Virginia.

Camerer, Colin. Behavioral Game Theory. New York: Russell Sage Foundation, 2003.

Checkovich, T.J. and S. Stern. 2002. Shared caregiving responsibilities of adult siblings with elderly parents. J. of Human Resources 37: 441-475.

Chiappori, Pierre-Andre. "Rational Household Labor Supply,” Econometrica, 56 (January, 1988): 63-90.

Couch, K.A., M.C. Daly, and D.A. Wolf. 1999. Time? Money? Both? The allocation of resources to older parents. Demography, 36(2): 219-32.

Cox, D. 1987. Motives for private income transfers. Journal of Political Economy. 95: 508-546.

Cox, Donald, and Stark, Oded. "Intergenerational Transfers and the 'Demonstration Effect'." Boston College, Working paper, 1996.

Cox, D., Z. Eser, and E. Jimenez. 1998. Motives for private transfers over the life-cycle: An analytic framework and evidence for Peru. J. of Development Economics, 55:57-80.

Cox, Donald, and Stark, Oded. "On the Demand for Grandchildren: Tied Transfers, Liquidity Constraints and the 'Demonstration Effect'.” Boston College, Working Paper, 2003.

Duncan, G.J., W.J. Yeung, J. Brooks-Gunn, and J.R. Smith. 1998. How much does childhood poverty affect the life chances of children? American Sociological Review, 63(3):406-23.

Ekah, P.P. 1974. Social exchange theory: Two traditions. Cambridge, MA: Harvard University Press.

Engers M. and S. Stern. 2001. Long-term care and family bargaining. International Economic Review, 43: 73-114.

Folbre, Nancy. "Cleaning House: New Perspectives on Households and Economic Development." Journal of Development Economics, 22 (\&\&\&\& 1986): 5-40.

Frankenberg, E., L. Lillard and R.J. Willis.2002. Patterns of Intergenerational Transfers in Southeast Asia. J. of Marriage and Family, 64: 627-641.

Fehr, E. and S. Gachter. 2002. Altruistic punishment in humans. Nature 415:137-140.Goldstein, H. 1995. Multilevel statistical models, second edition. London: Arnold. 
Hauser, R.M. and H.D. Kuo. 1998. Does gender composition of siblings affect women's education attainment. The Journal of Human Resources. 33: 644-657.

Henretta, J.C., M. S. Hill, W. Li, B. J. Soldo and D. A. Wolf. 1997. Selection of children to provide care: The effect of earlier parental transfers. Journal of Gerontology: Social Sciences. 52B: 110-119.

Hiedemann, B. and S. Stern. 1999. Strategic play among families when making long-term care decisions. Journal of Economic Behavior and Organization. 40: 29-57.

Hochguertel, Stefan and Henry Ohlsson, "Compensatory Inter-Vivos Gifts," Goteborg University Working Papers in Economics (No.31) (2000).

Hogan, D. P., D. J. Eggebeen, and C. C. Clogg. 1993. The structure of intergenerational exchanges in American families. American Journal of Sociology. 98: 1428-1458.

Homans, G.C. (1962 ) 1974. Social Behavior: Its Elementary Forms. NY: Harcourt Brace.

Juster, F. T. and R. Suzman. 1995. An overview of the Health and Retirement Study. Journal of Human Resources. 30(Supplement): S1-S30.

Kennan, John. "The Economics of Strikes," Chapter 19, Handbook of Labor Economics O. Ashenfelter and R. Layard, eds. New York: Elsevier Science Publishers, 1986.

Kuo, H.D. and R.M. Hauser.1996. Gender, family configuration, and the effect of family background on educational attainment. Social Biology 43: 98-131.

Lawler, E., S.R.Thye, and J. Yoon. 2000. Emotion and group cohesion in productive exchanges. American Journal Of Sociology, 106 (3): 616-57.

Laitner, J. Intergenerational and interhousehold economic links. Pp. 189-240 in Handbook of Population and family Economics. Edited by M.R. Rosenzweig and O. Stark, Amsterdam: Elsevier.

Leigh, Geoffrey K. "Kinship Interaction over the Family Life Span." Journal of Marriage and the Family 44 (February,1982): 197-208.

Lerner, M.J., Somers, D.G., Reid, D. Chiriboga, D. and Tierney, M. "Adult Children as Caregivers: Egocentric Biases in Judgments of Sibling Contributions." The Gerontologist 31 (\&\&\&\& 1991): 746-755.

Levi-Stauss, C. 1969. The Elementary Structures of Kinship. Boston: Beacon Press.

Liu, K., K.G. Manton, and C. Aragon. 2000. Changes in home care use by disabled elderly persons: 19821994. Journal of Gerontology: Social Sciences, 55B: S245-253. 
Lundberg, Shelly, and Pollak, Robert A. "Separate Spheres Bargaining and the Marriage Market." Journal of Political Economy 101 (December 1993): 988-1010.

Manser, Marilyn, and Brown, Murray. "Marriage and Household Decision Making: A bargaining Analysis." International Economic Review 21 (February 1980): 31-44.

Martin, T.C. and L. L. Bumpass.1989. Recent trends in marital disruption. Demography 26:59-82.

Mauss, A. 1954[1925]. The Gift. Glencoe, IL: Free Press.

McElroy, Marjorie and Horney, Karen. "Nash-bargained Household Decisions: Toward a Generalization of the Theory of Demand.” International Economic Review 22 (June 1981): 333-349.

McGarry, K. and R.F. Schoeni. 1995. Transfer behavior: Measurement and the redistribution of resources within the family. Journal of Human Resources, 30: S184-S226.

McGarry, K. and R.F. Schoeni. 1997. Transfer behavior within the family: Results from the Asset and Health Dynamics Study. Journal of Gerontology: Social Sciences. 52B: 82-91.

McLanahan, S. and G. Sandefur. 1994. Growing up with a single parent. Cambridge: Harvard University Press.

Molm, L. and K. Cook.1995. Social exchange and exchange networks. Pp. 209-35 in Sociological Perspectives on Social Psychology. Edited by K. Cook, G. Fine and J. House, Boston: Allyn and Bacon.

Neuharth, T. J. and S. Stern. 1998. Shared caregiving responsibilities of adult siblings with elderly parents. Unpublished paper, University of Virginia.

Pezzin, L.E. and B.S. Schone. 1999a. Intergenerational household formation, female labor supply and informal caregiving: A bargaining approach. Journal of Human Resources. 34(3): 475-50

Pezzin, L.E. and B.S. Schone. 1999b. Parental marital disruption and intergenerational transfers: An analysis of lone elderly parents and their children. Demography. 36:287-297.

Ribar, D.C. and M.O. Wilhelm. 2001. The intergenerational transmission of exchange attitudes: Evidence of generalized exchange from three generations of Mexican-Americans. Mimeograph, Dept of Economics, The George Washington University, Washington DC.

Rosenzweig, M.R. and K.I. Wolpin. 1994. Intergenerational support and the life-cycle incomes of young men and their parents: Human capital investments, coresidence, and inergenerational financial transfers. Journal of Labor Economics 11(1): 84-1112. 
Santos-Pinto, Luis. "Positive Self-image and Incentives in Organizations." Working Paper, University of California, San Diego, November, 2003.

Sloan, F.A., G. Picone, and T.J. Hoerger. 1997. The supply of children's time to disabled elderly parents. Economic Inquiry 35: 295-308.

Sober, E. and Wilson, D.F. 1998. Unto Others: The Evolution and Psychology of Unselfish Behavior. Cambridge , MA.: Harvard University Press.

Soldo, B.J., D.A. Wolf, and E.M. Agree. 1990. Family, household, and care arrangements of frail older women, Journal of Gerontology: Social Sciences, 45(6) S238-249.

Soldo, B.J. and M.S. Hill. 1993. Intergenerational transfers: Economic, demographic, and social perspectives. Annual Review of Gerontology and Geriatrics, 13:187-216.

Soldo, B.J. and V.A. Freedman. 1994. Care of the elderly: Division of labor among the family, market, and state. Pp. 195-216 in Demography of Aging. Edited by L. Martin and S.H. Preston Washington, D.C.: National Academy Press.

Soldo, B.J. and M.S. Hill. 1995. Family structure and transfer measures in the Health and Retirement Study: Background and overview. Journal of Human Resources 30: S108-37.

Soldo, B. J., D. A. Wolf, and J. C. Henretta. 1999. Intergenerational transfers: Blood, marriage, and gender effects on household decisions. Pp. 335-355 in Wealth, Work, and Health: Innovations in Survey Measurement in the Social Sciences. Edited by J. P. Smith and R. J. Willis. Ann Arbor, MI: University of Michigan Press.

Spitze, G. and J. Logan. 1990. Sons, daughters, and intergenerational support. Journal of Marriage and the Family, 52:420-430.

Stark, O. 1995. Intrafamilial transfers and exchanges: Forming and sustaining altruism. Pp. 119-136 in O. Stark, Altruism and Beyond. Cambridge University: Cambridge University Press.

Stern, S. 1995. Estimating family long-term care decisions in the presence of endogenous child characteristics. Journal of Human Resources, 30 (3): 551-580.

Stoller, Eleanor P. "Parental Caregiving by Adult Children." Journal of Marriage and the Family 45 (November 1983): 851-858.

Teachman, J.D., L.M. Tedrow, and Kyle D. Crowder. 2000. The changing demography of America's Families. J. of Marriage and the Family 62:1234-1246. 
Tomassini, C. and D.A. Wolf. 2000. Shrinking networks in Italy due to sustained low fertility. European Journal of Population, 16:353-372.

Tomassini, C., D.A. Wolf, and A. Rosina. 2001. Parental housing assistance and parent-child proximity in Italy. Paper presentation at the Annual Meeting of the Population Association of America, Washington DC.

Tomes, Nigel. "The Family, Inheritance, and the Intergenerational Transmission of Inequality." Journal of Political Economy 89 (October 1981): 928-958.

Wolf, D.A. 1994. The elderly and their kin: Patterns of availability and access. Pp. 146-94 in L. Martin and S.H. Preston (eds.), Demography of Aging Washington, D.C.: National Academy Press.

Wolf, D.A. and B.J. Soldo.1988. Household choices of older unmarried women, Demography, 25(3): 387403.

Wolf, D.A. and B.J.Soldo. 1994. Married women's allocation of time to employment and care of elderly parents. Journal of Human Resources, 29 (4): 1259 - 1276.

Wolf, D.A., V. Freedman, and B.J. Soldo. 1997. The division of family labor: Care for elderly parents. Journals of Gerontology, Series B. 52B(Special Issue): 102-109. 


\section{Appendix—Module Questions and Code Counts}

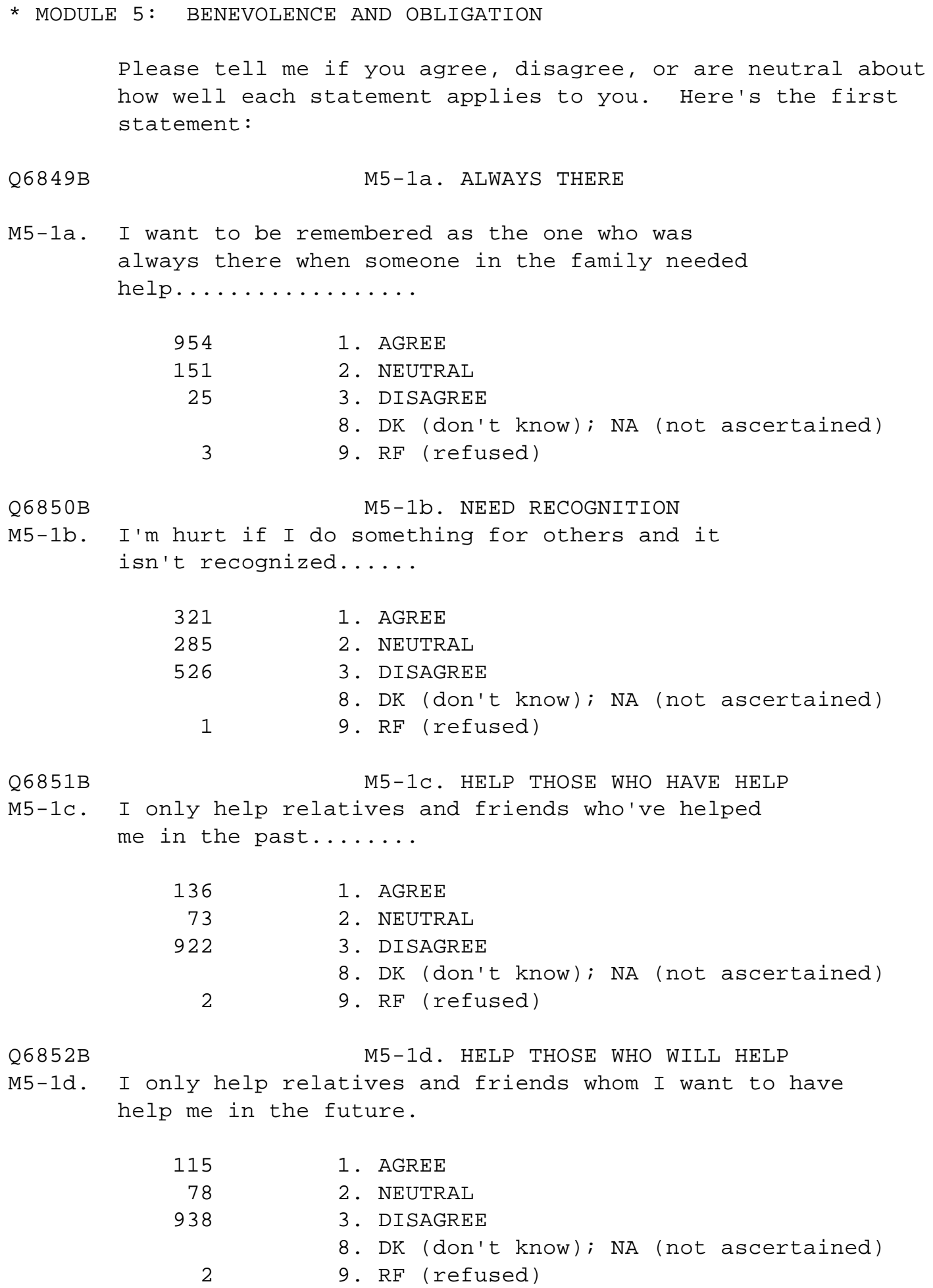




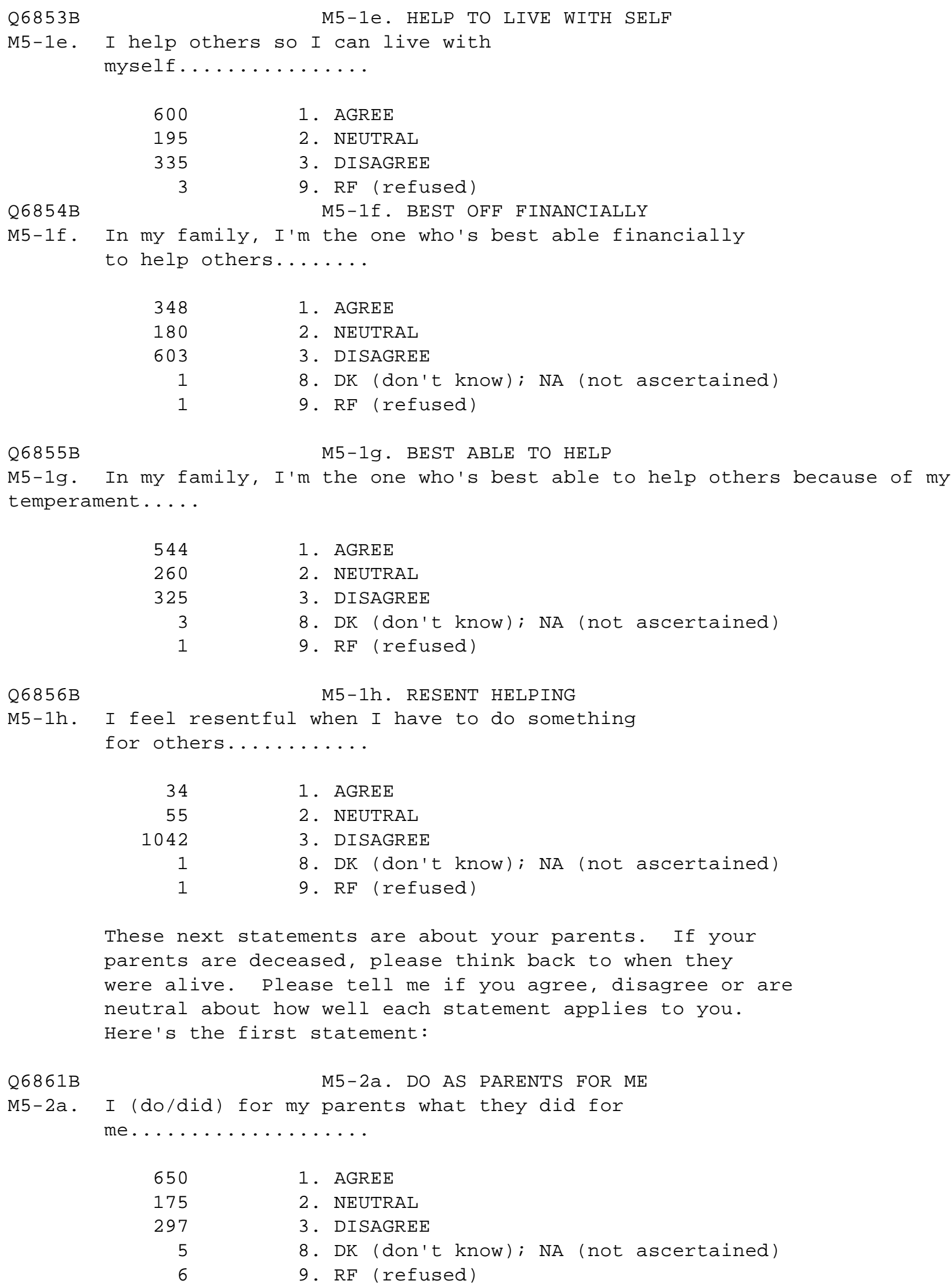




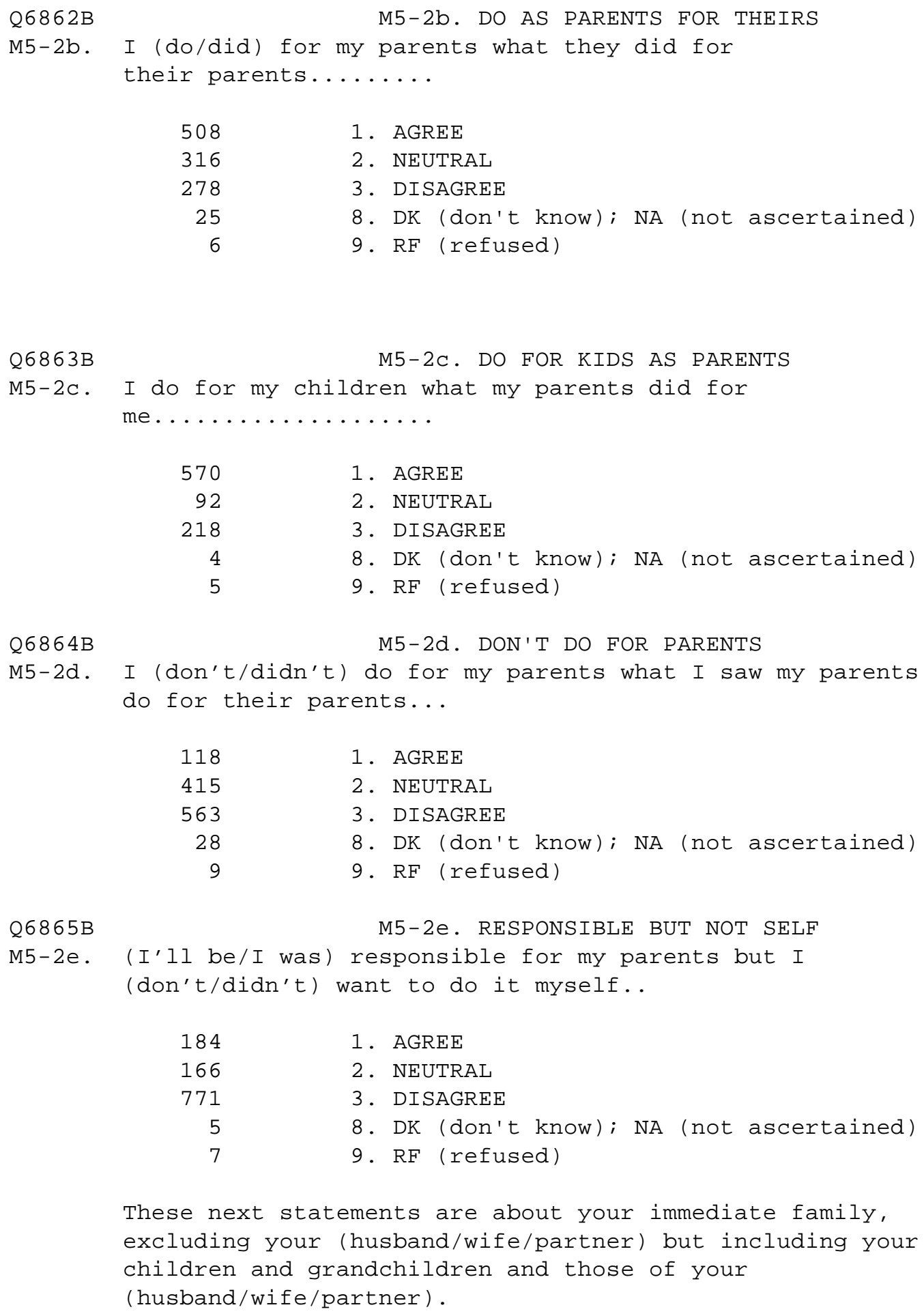




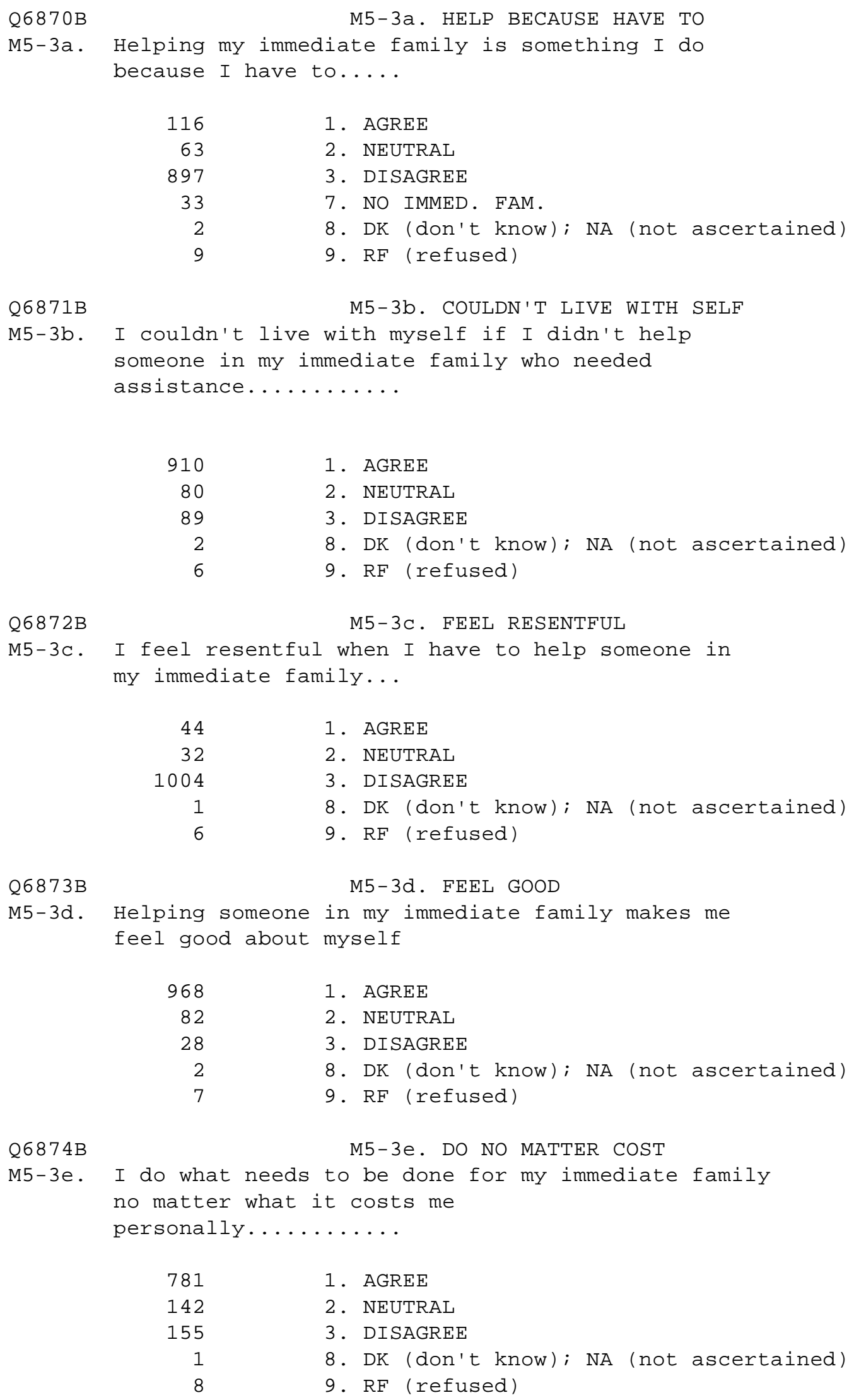




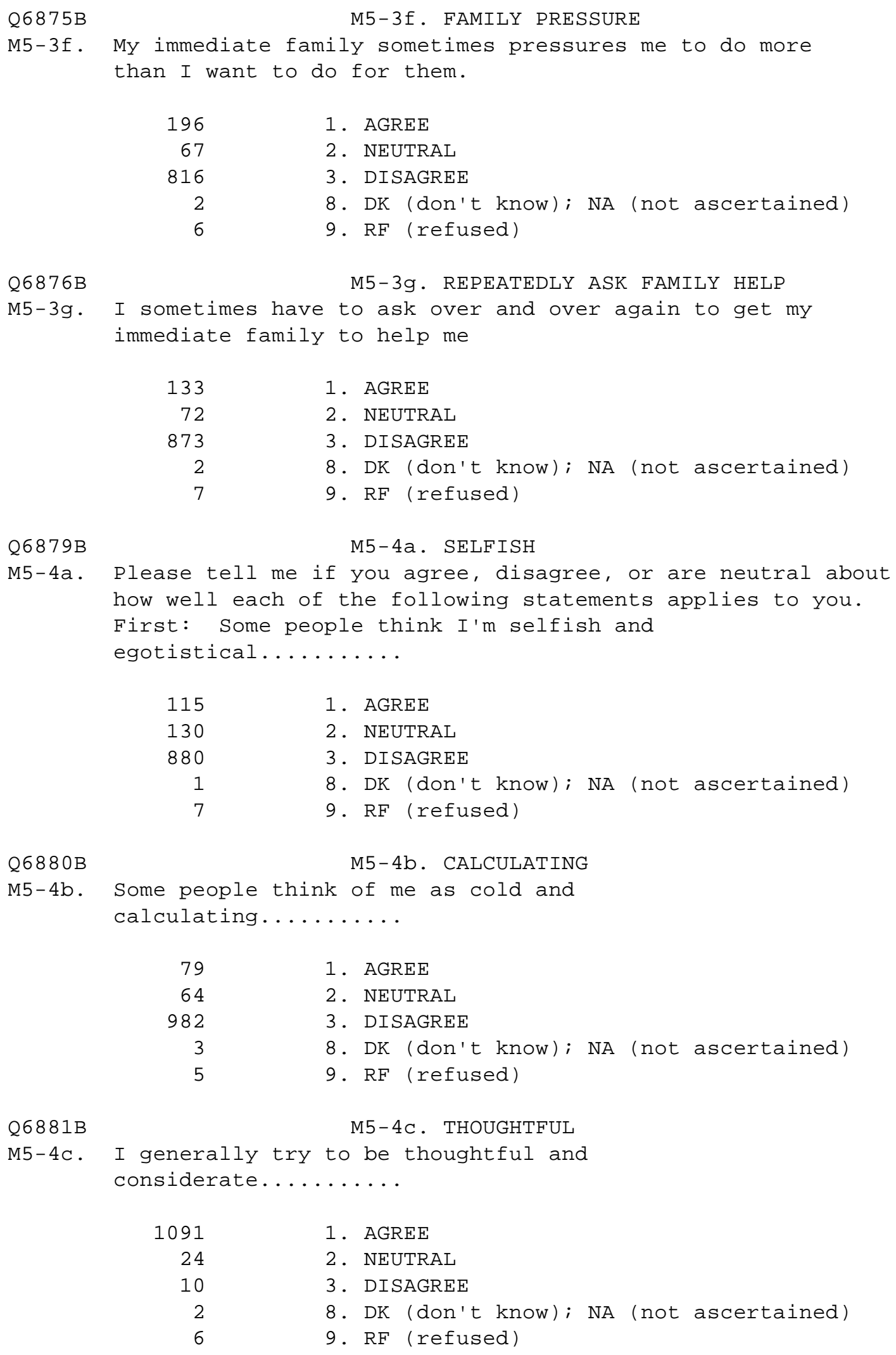




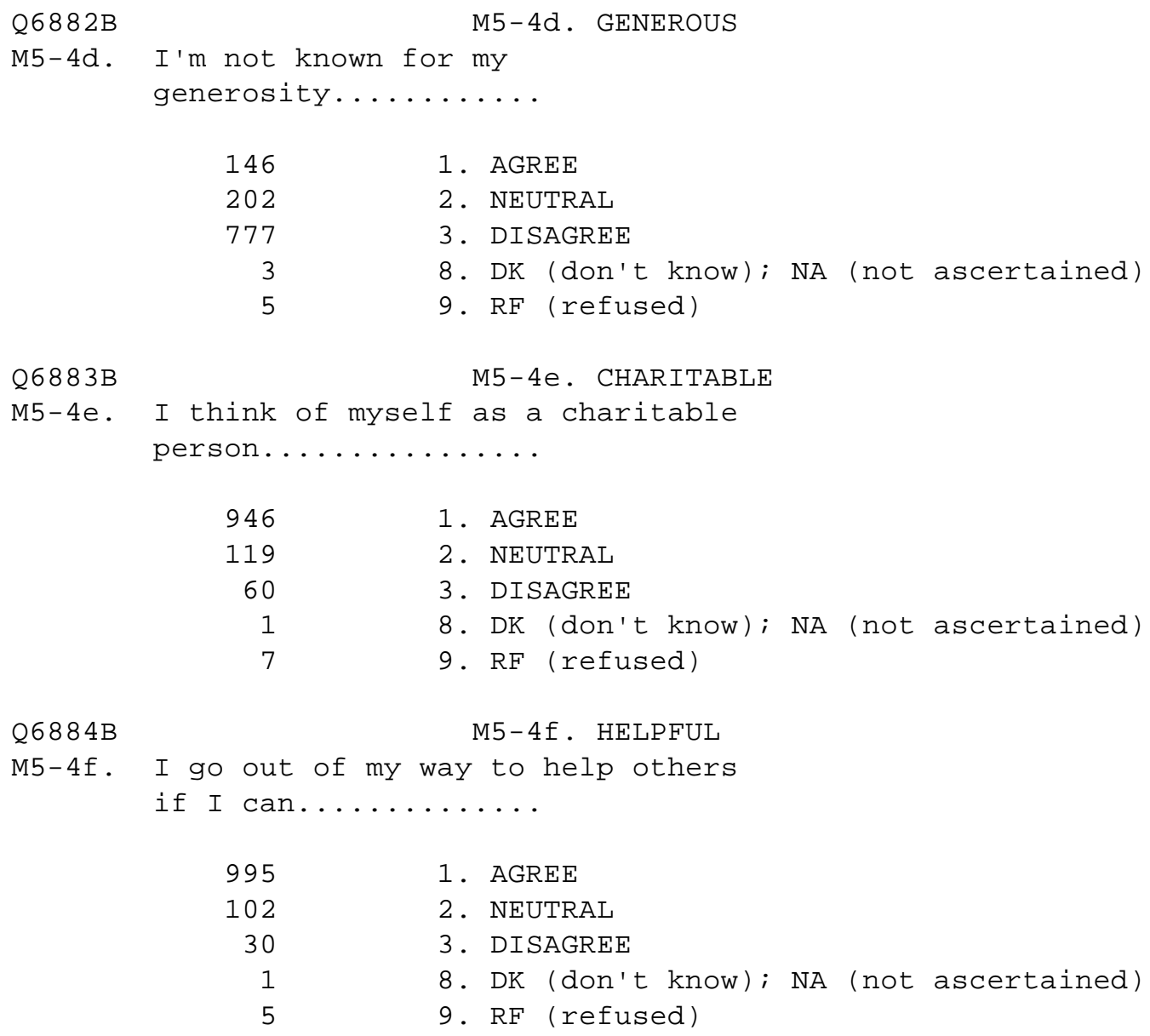



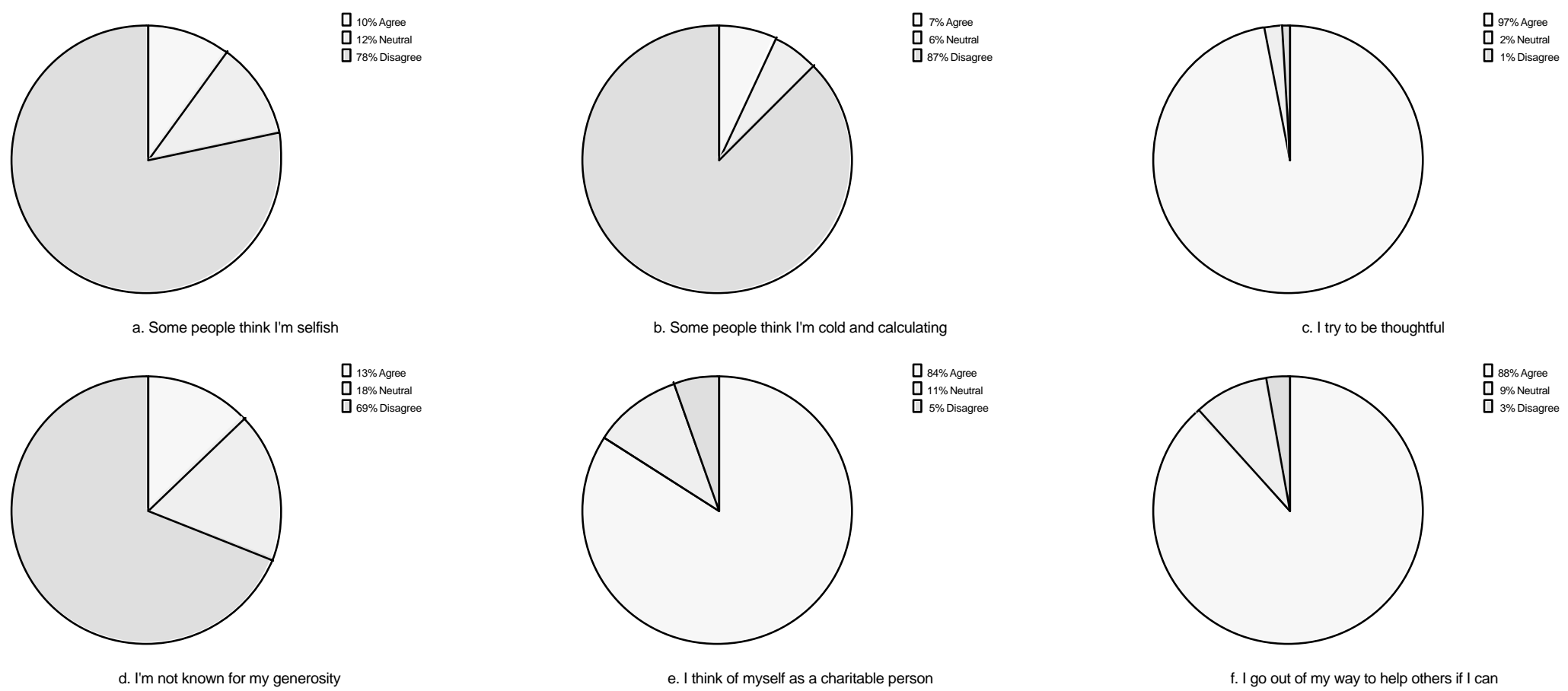

Figure 1. Respondent Self Image Regarding Their Altruism 

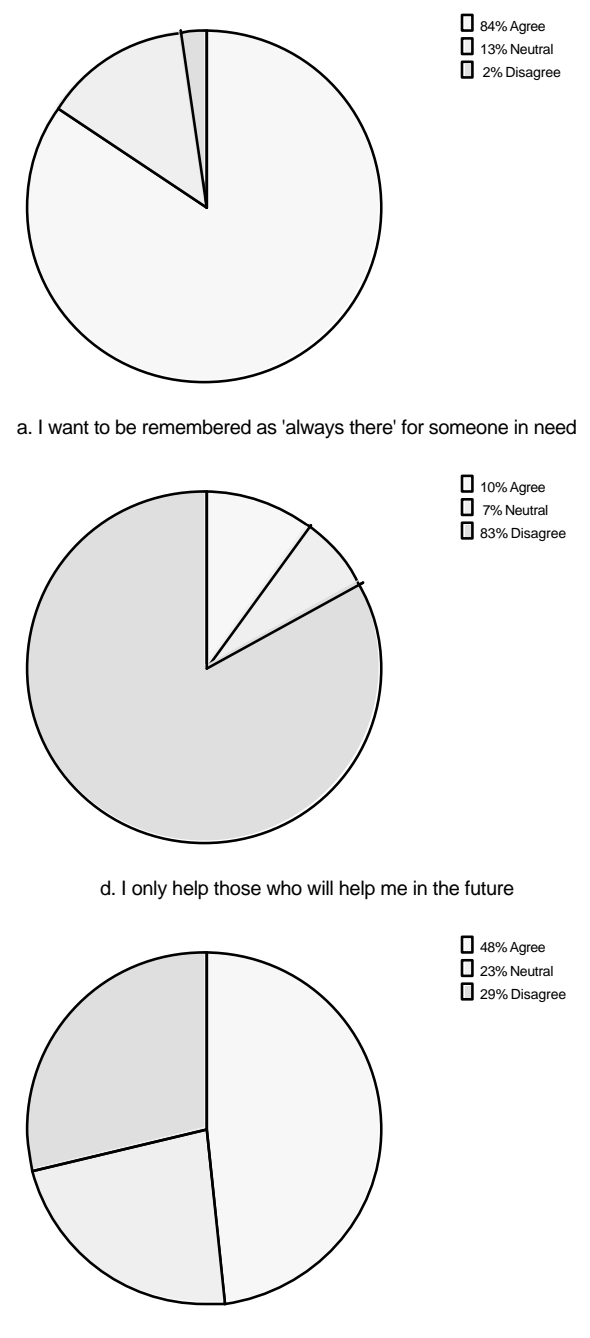
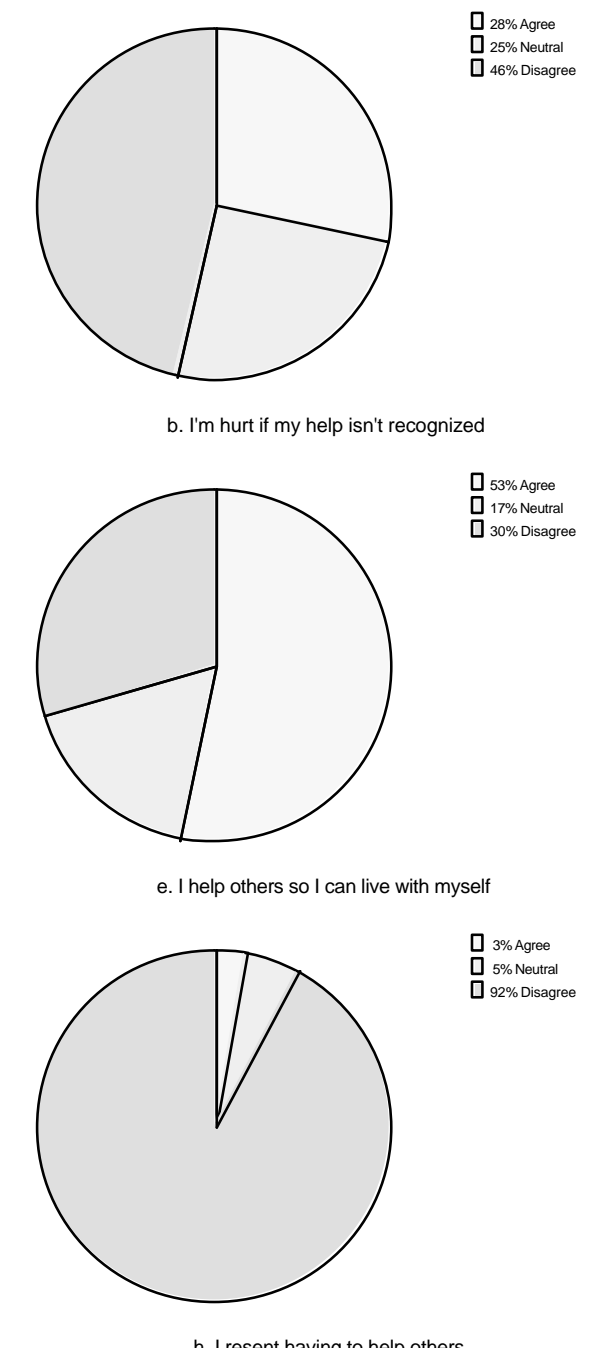
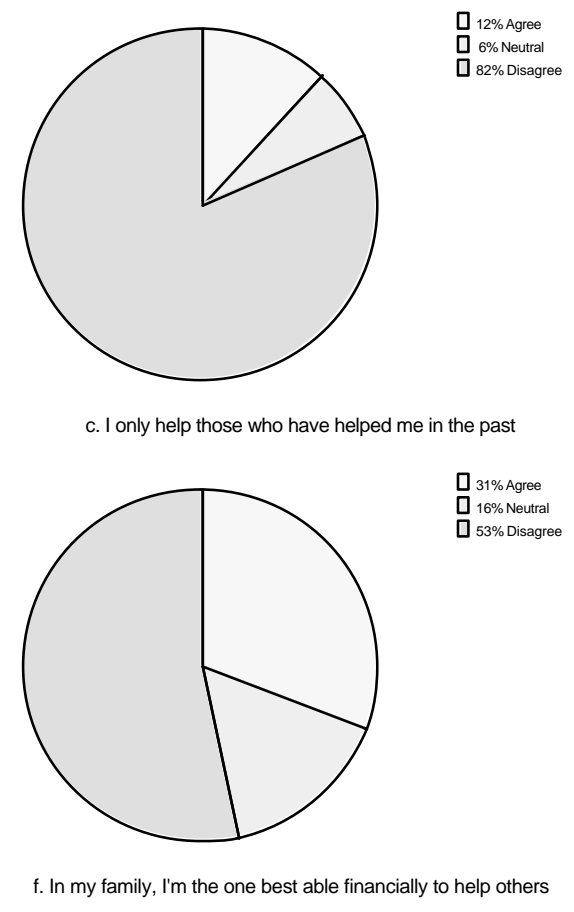

f. In my family, I'm the one best able financially to help others

Figure 2. How Respondents See Themselves as Family Helpers 


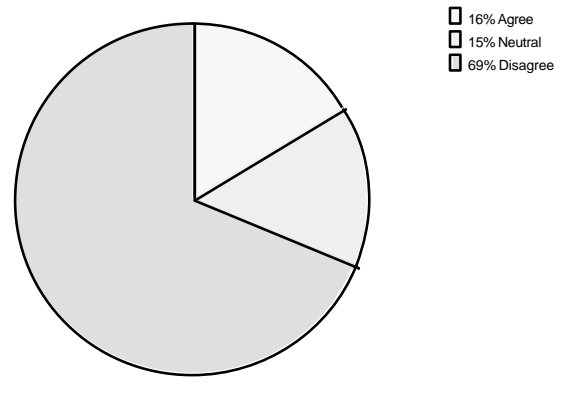

a. I Don't (didn't) want sole responsibility for parents
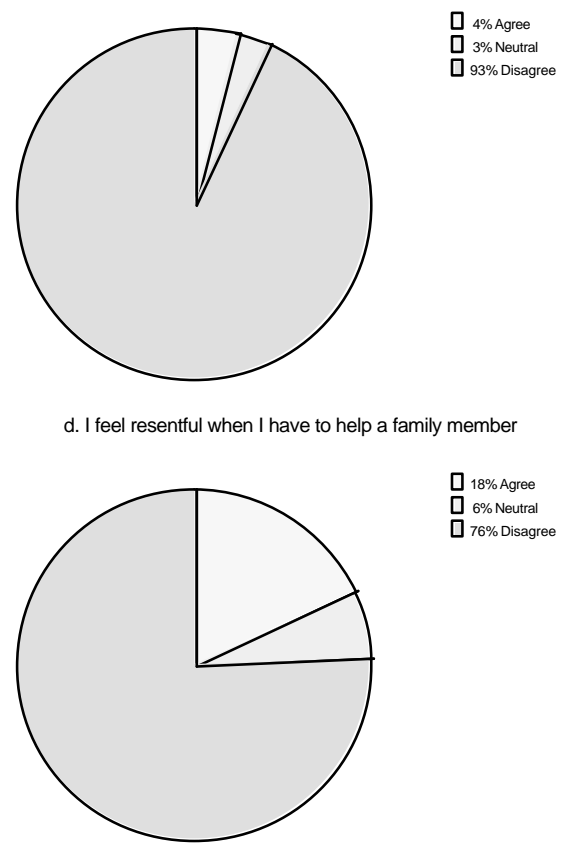

g. My family sometimes pressures me to help more than I want
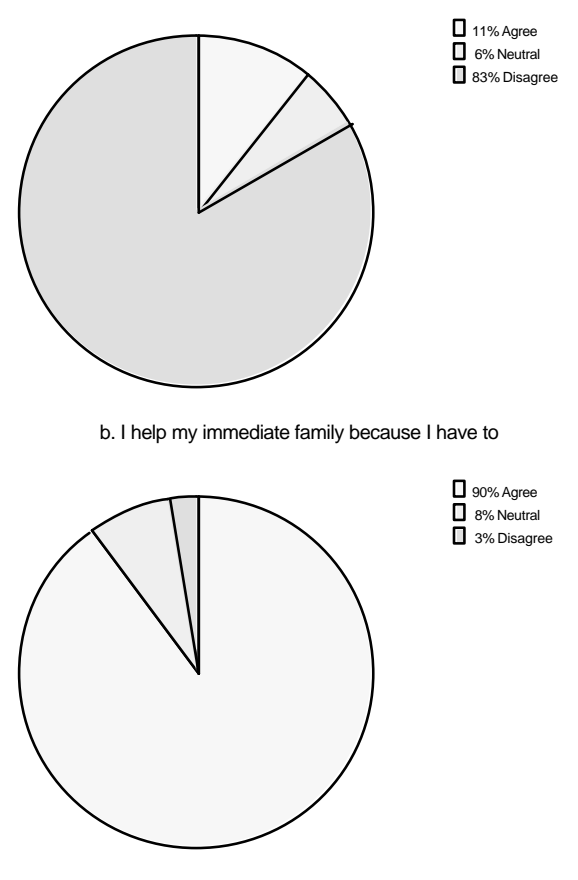

e. Helping a family member makes me feel good about myself

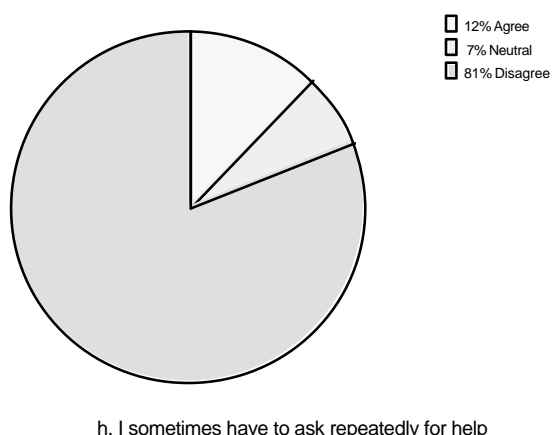

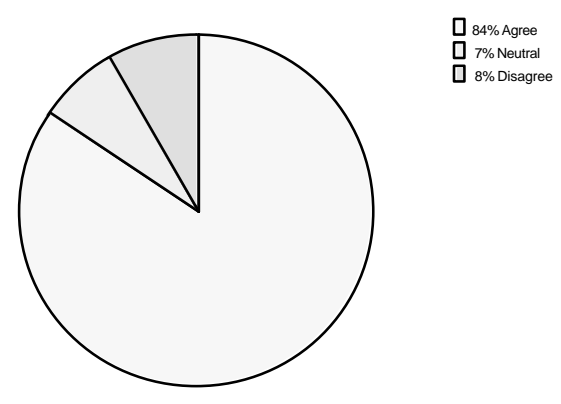

c. I couldn't live with myself if I didn't provide needed help

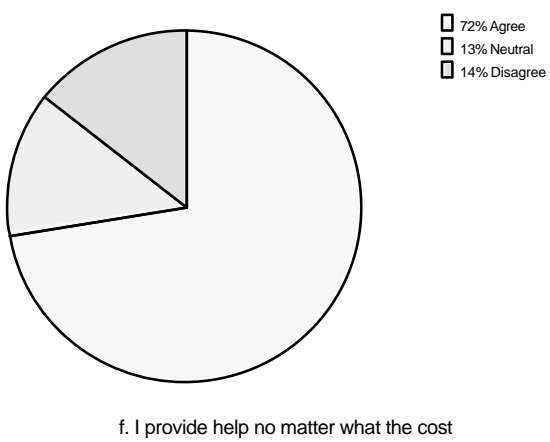

Figure 3. Attitudes About Helping within the Family 


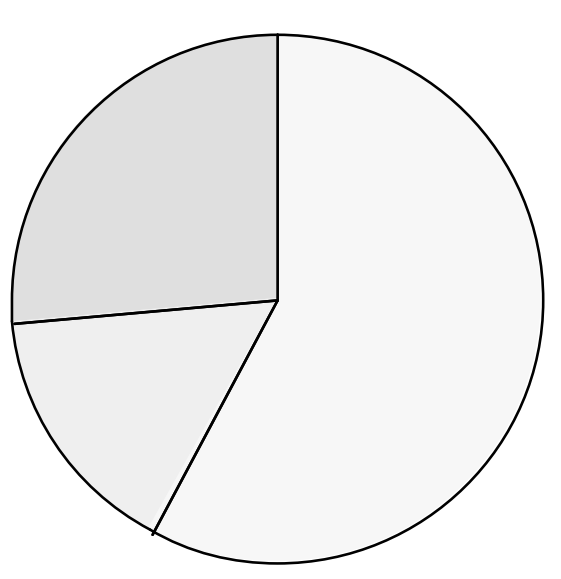

a. I do (did) for my parents what they did for me

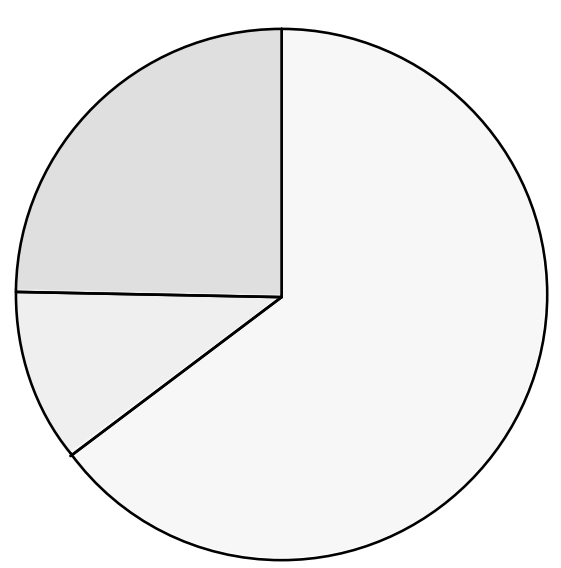

c. I do for my kids what my parents did for me

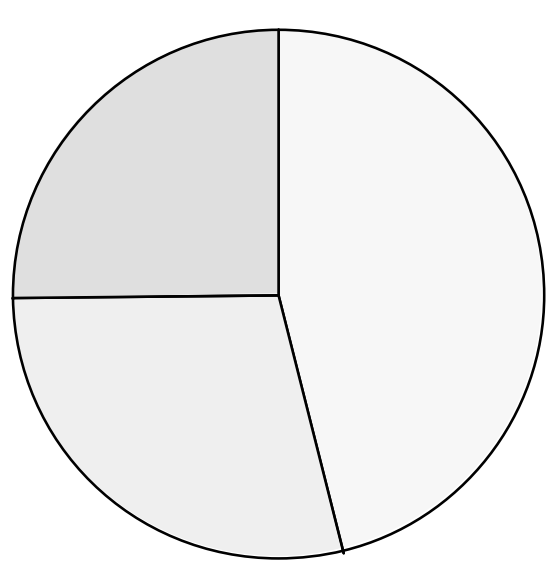

$\square$ 46\% Agree

$29 \%$ Neutral

$\square 16 \%$ Neutral

b. I do (did) for my parents what they did for their parents

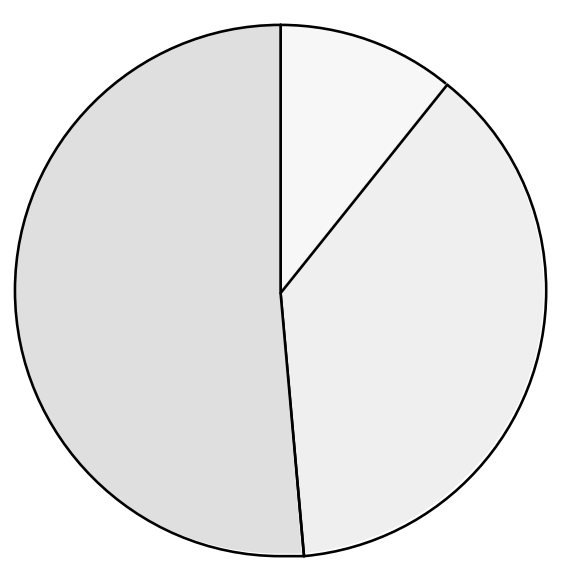

$11 \%$ Agree

$38 \%$ Neutral

$\square 51 \%$ Disagree

Figure 4. Parental Influences on Family Help 


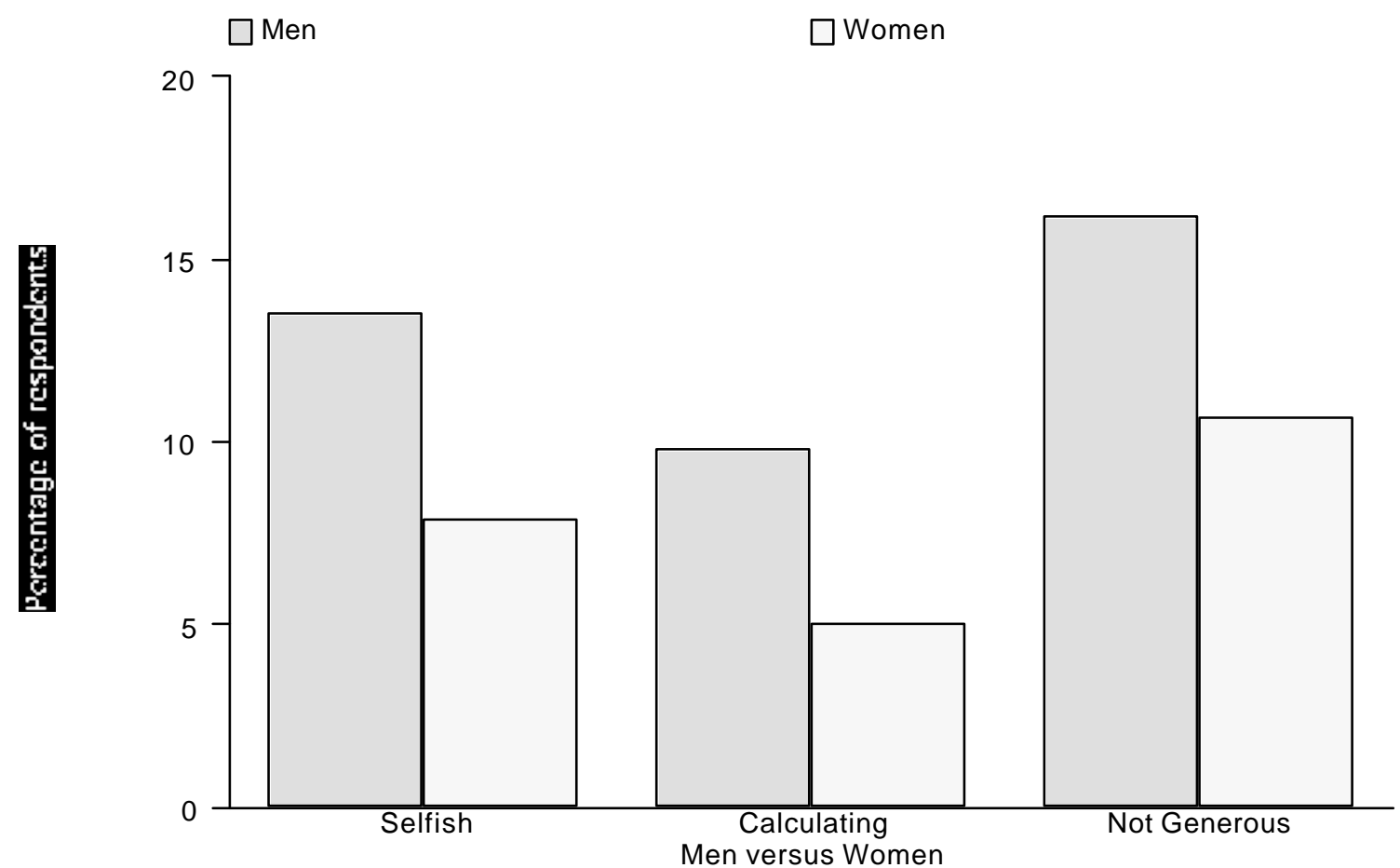

Figure 5. Men's and Women's Responses About Not Being Nice 


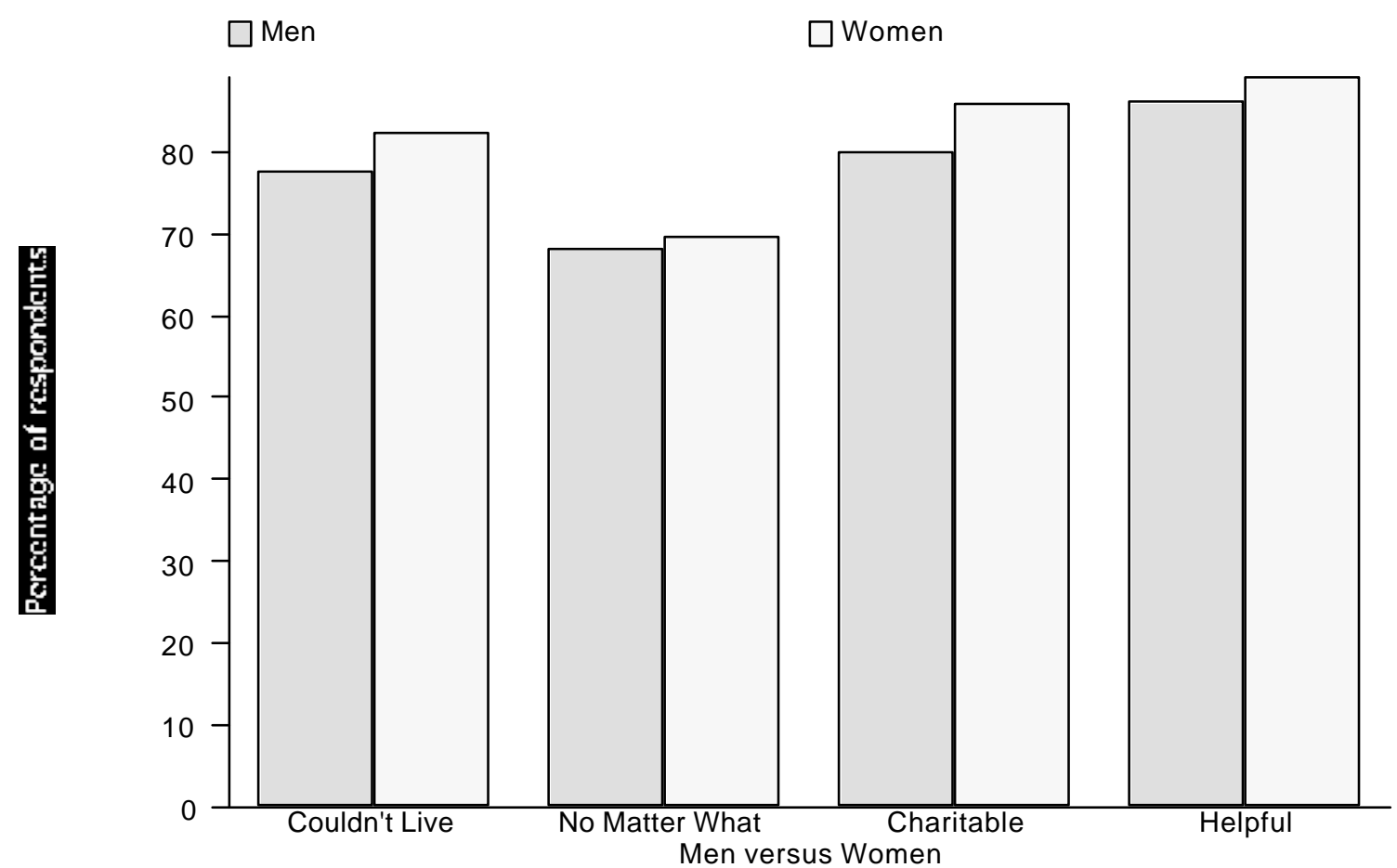

Figure 6. Men's and Women's Responses About Being Nice

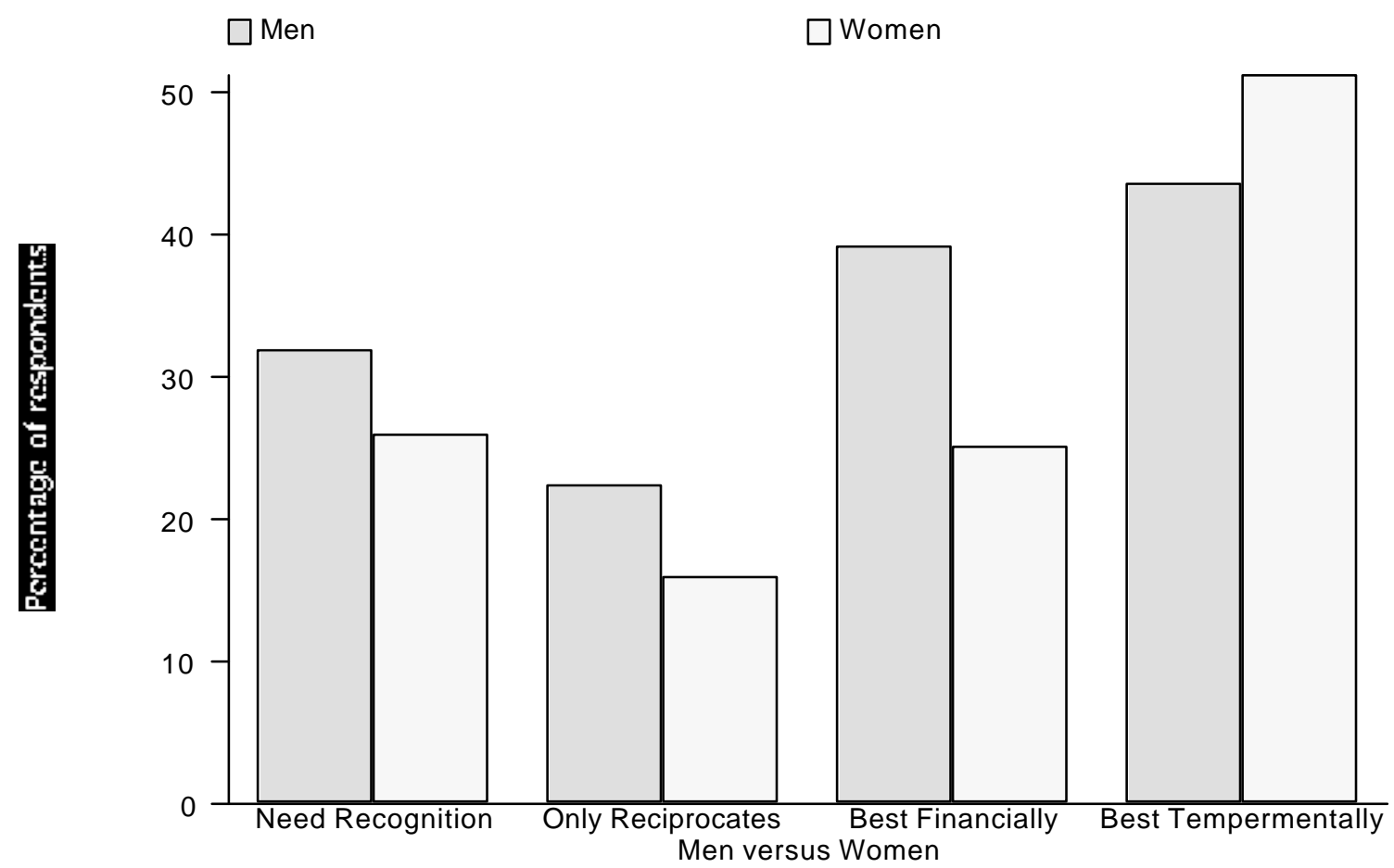

Figure 7. How Men and Women See Themselves as Family Helpers 


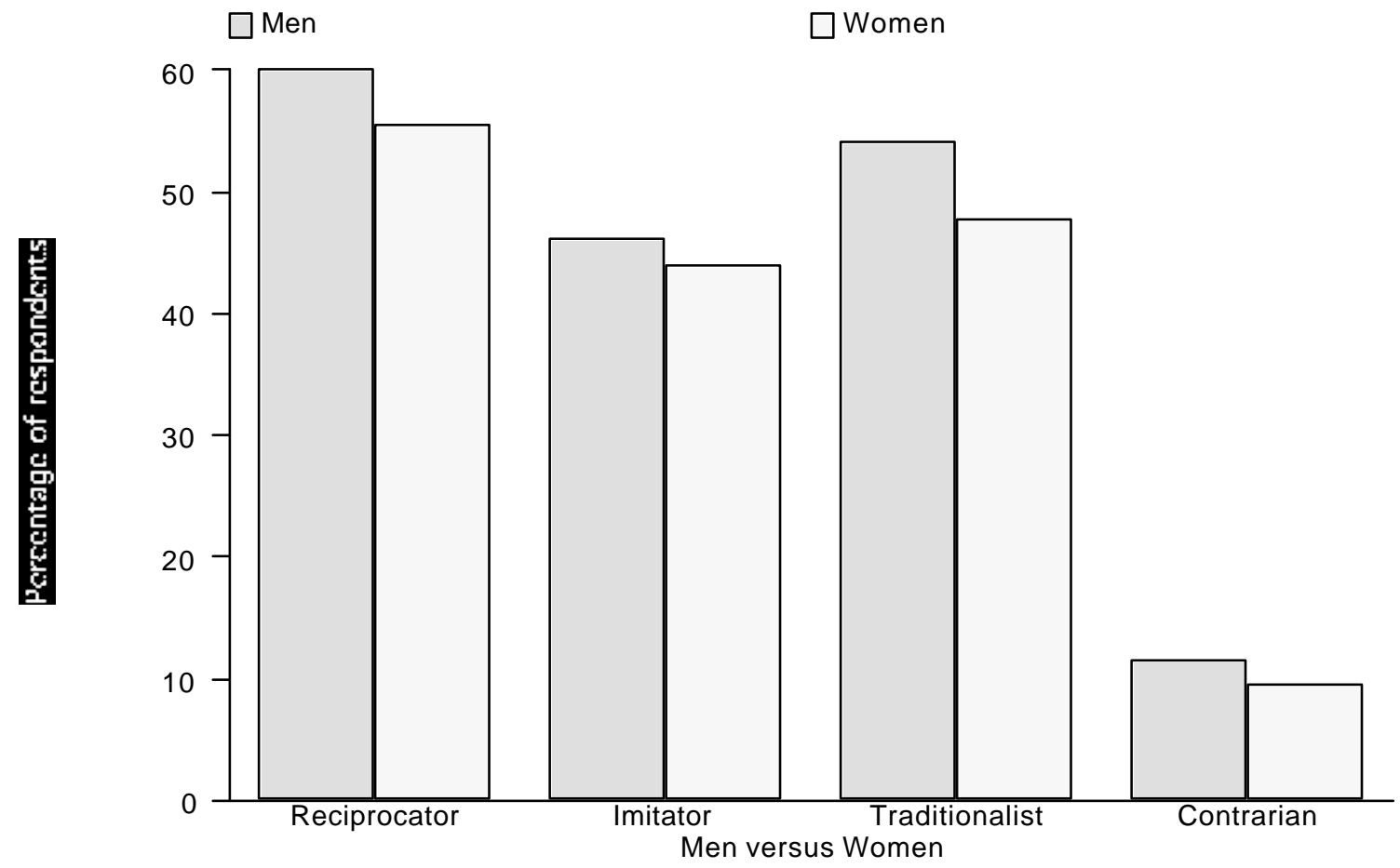

Figure 8. How Men and Women Are Affected by Their Parents

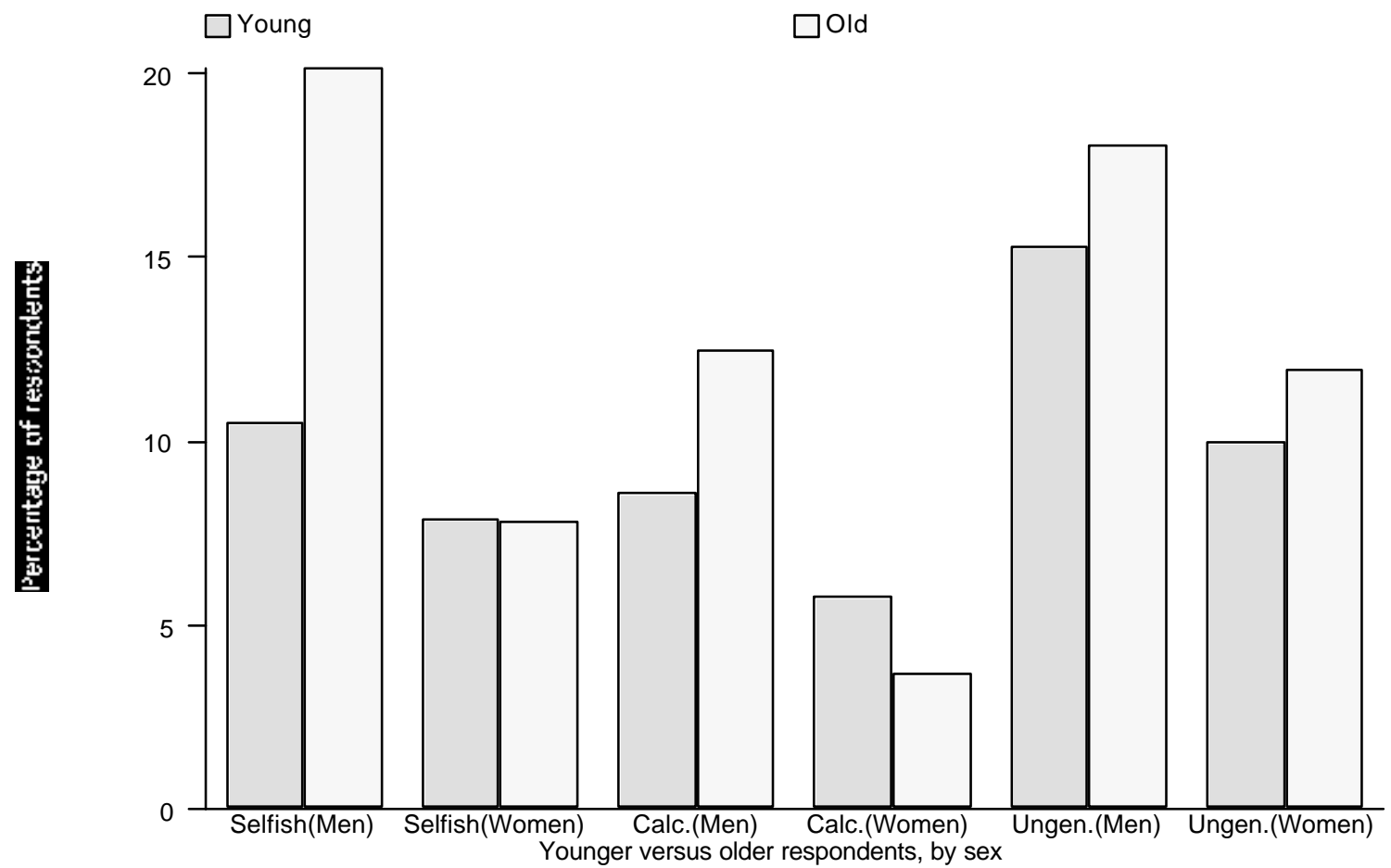

Figure 9. Aging and Responses About Not Being Nice 


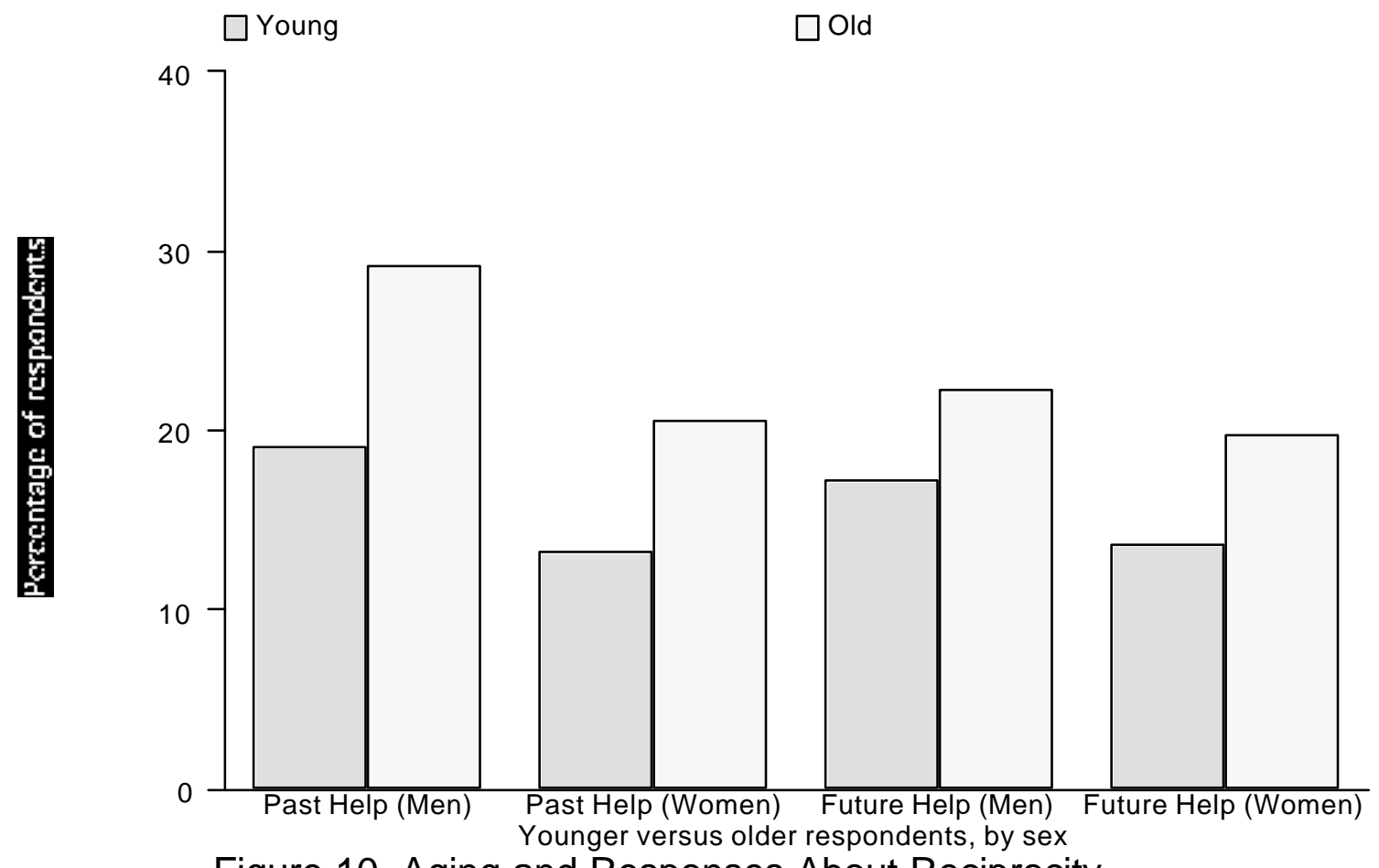

Figure 10. Aging and Responses About Reciprocity

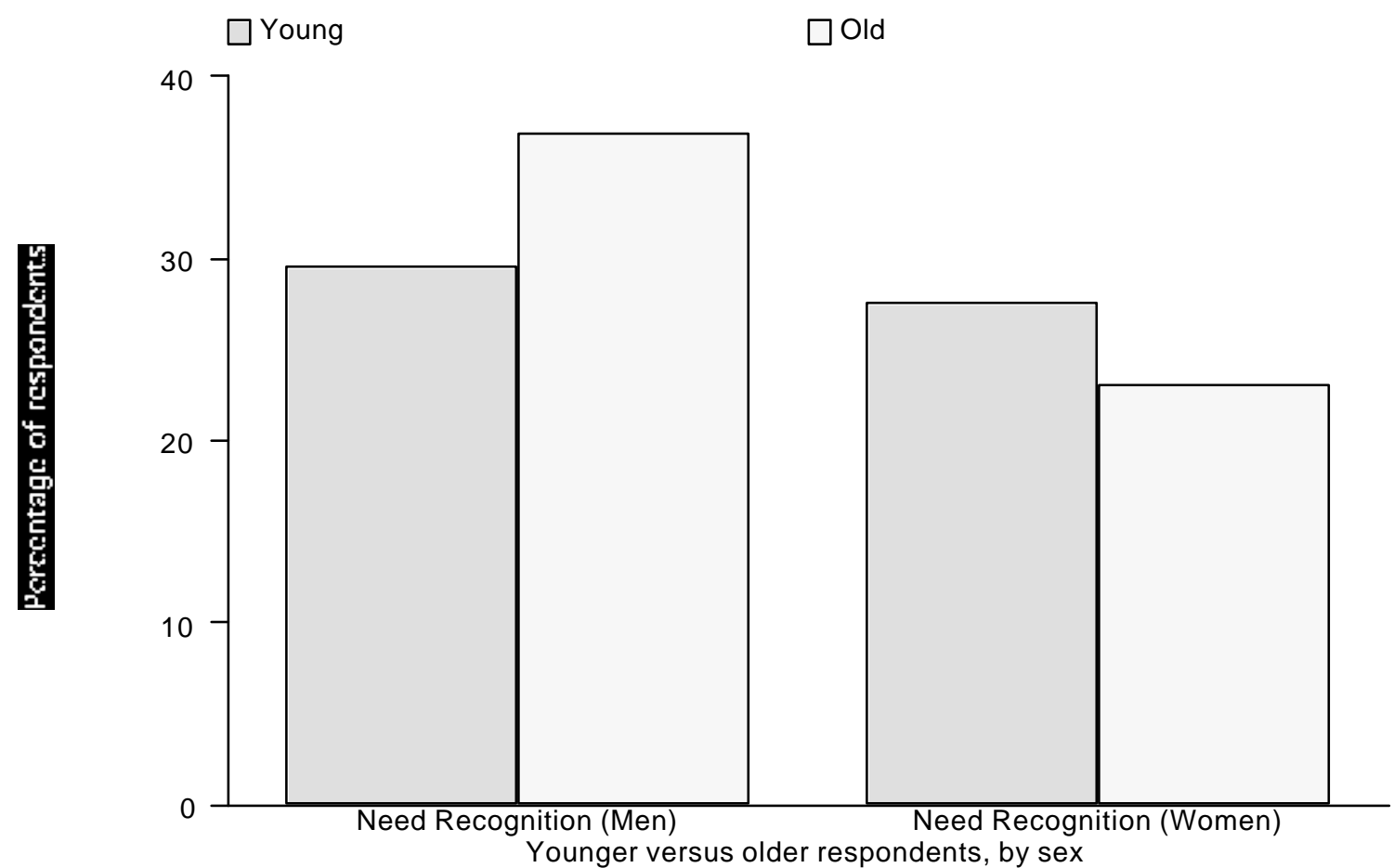

Figure 11. Aging and the Need for Recognition 


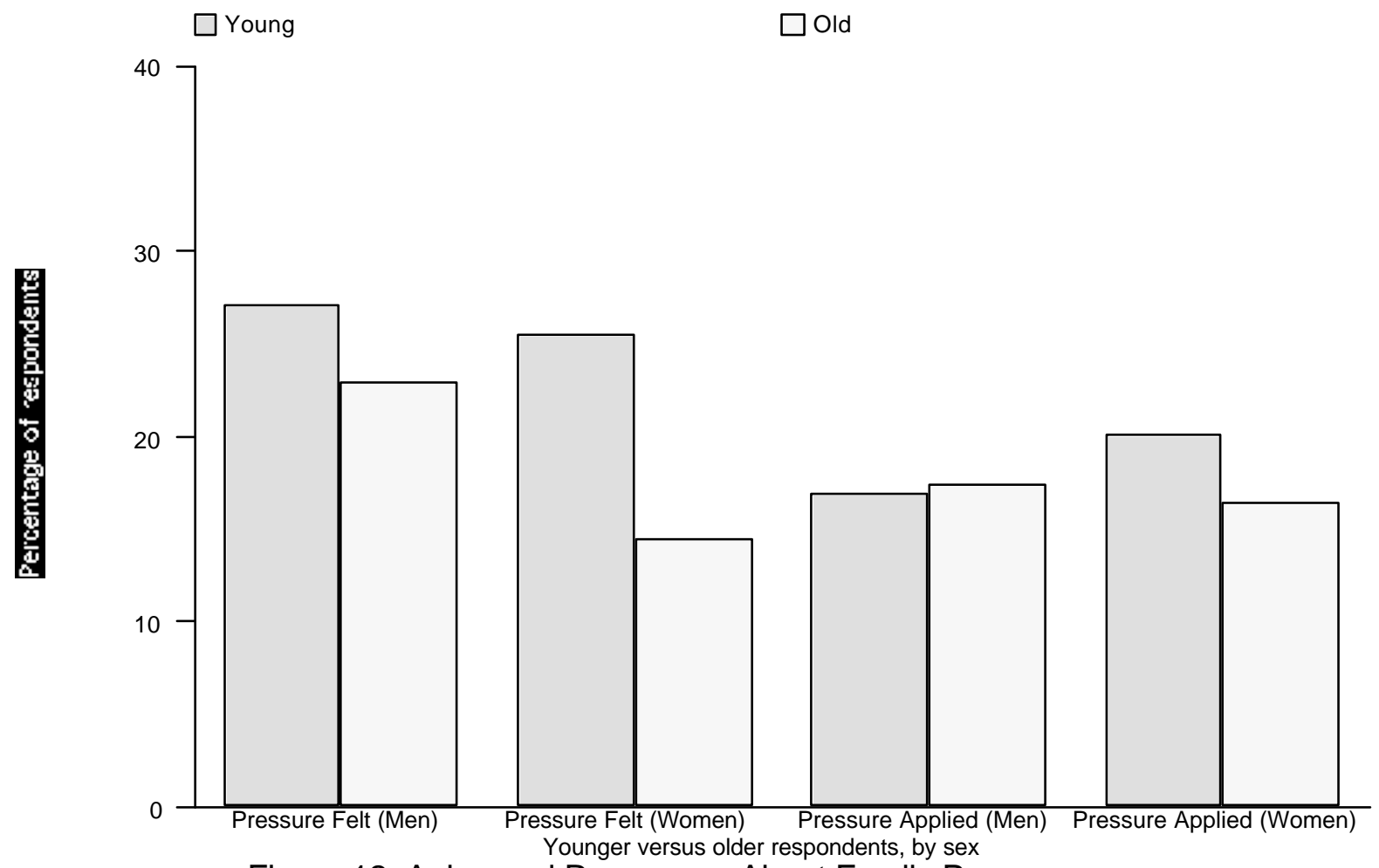

Figure 12. Aging and Responses About Family Pressure

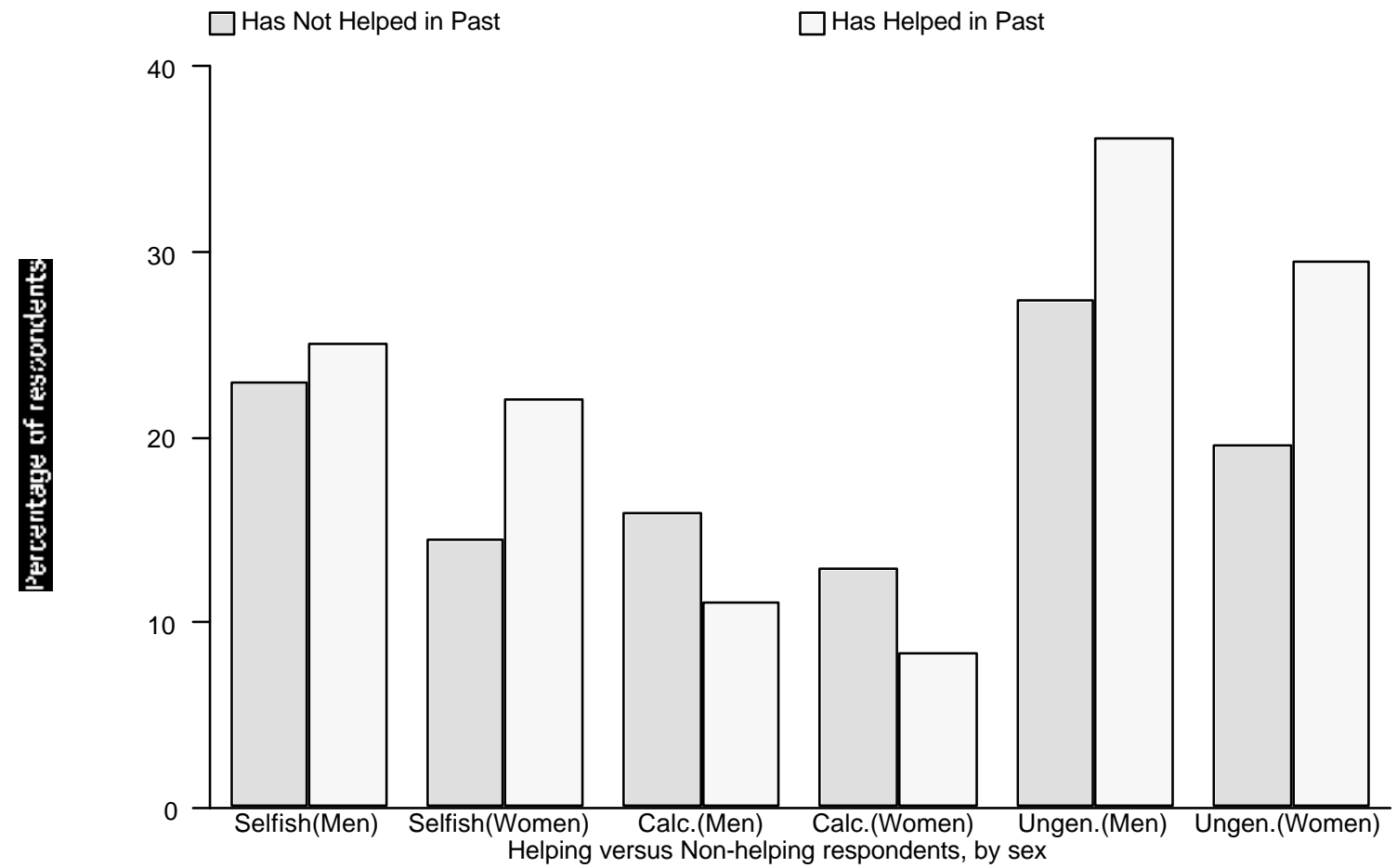

Figure 13. Past Help Provided and Responses About Not Being Nice 


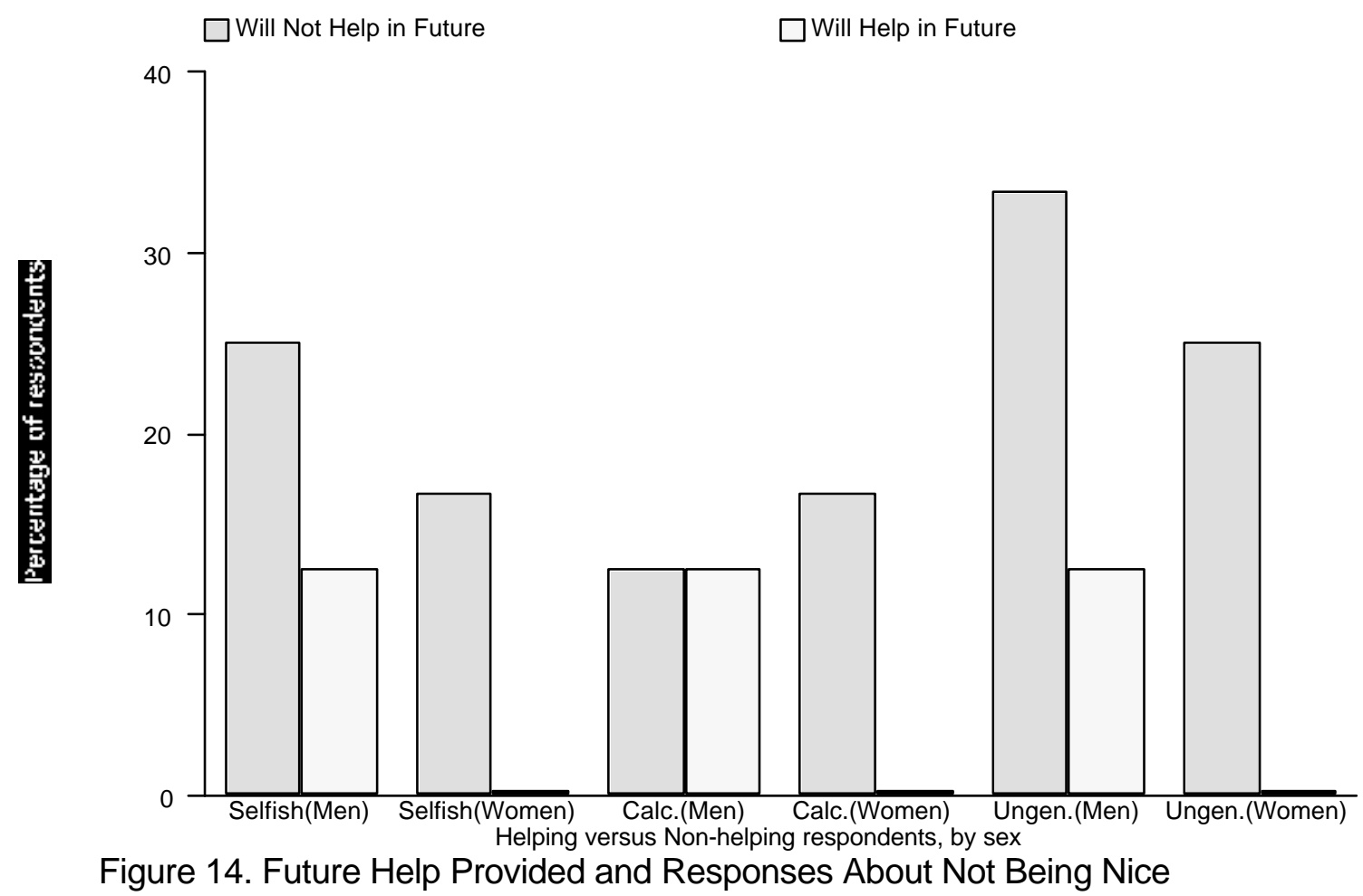




\section{RECENT WORKING PAPERS FROM THE}

\section{CENTER FOR RETIREMENT RESEARCH AT Boston COLLEGE}

Large, Small, International: Equity Portfolio Choices in a Large 401(k) Plan Julie Agnew and Pierluigi Balduzzi, May 2004

An Analysis of How Individuals React to Market Returns in One 401(k) Plan Julie Agnew, April 2004

The Effects of Health Insurance and Self-Insurance on Retirement Behavior

Eric French and John Bailey Jones, April 2004

Valuing Assets in Retirement Saving Accounts

James M. Poterba, April 2004

Lifetime Earnings, Social Security Benefits, and the Adequacy of Retirement Wealth Accumulation

Eric M. Engen, William G. Gale, and Cori Uccello, April 2004

The Effect of Social Security on Divorce and Remarriage Behavior Stacy Dickert-Conlin and Cristian Meghea, April 2004

Household Demand for Variable Annuities

Jeffrey R. Brown and James M. Poterba, March 2004

Lessons for an Aging Society: The Political Sustainability of Social Security Systems Vincenzo Galasso and Paola Profeta, March 2004

Choice and Other Determinants of Employee Contributions to Defined

Contribution Plans

Leslie E. Papke, March 2004

Linking Benefits to Marital Status: Race and Diminishing Access to Social Security Spouse and Widow Benefits in the U.S.

Madonna Harrington Meyer, Douglas A. Wolf, and Christine L. Himes, March 2004

Annuitization: Keeping Your Options Open

Irena Dushi and Anthony Webb, March 2004

Living Arrangements and Supplemental Security Income Receipt Among the Aged Melissa M. Favreault and Douglas A. Wolf, February 2004

All working papers are available on the Center for Retirement Research website

(http://www.bc.edu/crr) and can be requested by e-mail (crr@bc.edu) or phone (617-552-1762). 